Portland State University

PDXScholar

1986

\title{
The performance of reading disabled 3rd to 6th graders on the Token test for children
}

Jane J. Kihara

Portland State University

Follow this and additional works at: https://pdxscholar.library.pdx.edu/open_access_etds

Part of the Speech Pathology and Audiology Commons Let us know how access to this document benefits you.

Recommended Citation

Kihara, Jane J., "The performance of reading disabled 3rd to 6th graders on the Token test for children" (1986). Dissertations and Theses. Paper 3694.

https://doi.org/10.15760/etd.5578

This Thesis is brought to you for free and open access. It has been accepted for inclusion in Dissertations and Theses by an authorized administrator of PDXScholar. Please contact us if we can make this document more accessible: pdxscholar@pdx.edu. 
AN ABSTRACT OF THE THESIS OF Jane J. Kihara for the Master of Science in Speech Communication, with an emphasis in Speech-Ianguage Pathology, presented June 6,1986 .

Title: The Performance of Reading Disabled 3rd to 6th Graders on the Token Test for Children.

APPROVED BY MEMBERS OF THE THESIS COMMITTEE:

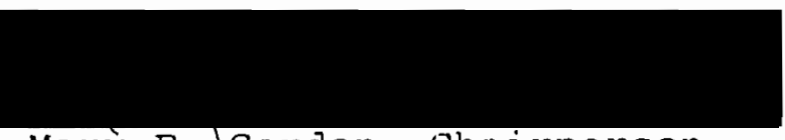

Marý EWGordon, Chairperson

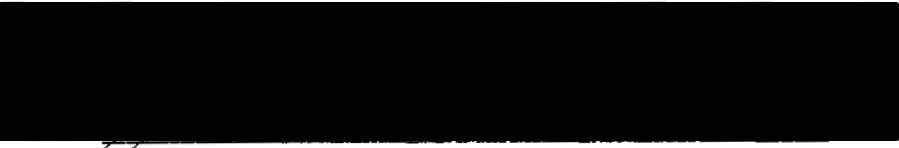

Zoan McMahon

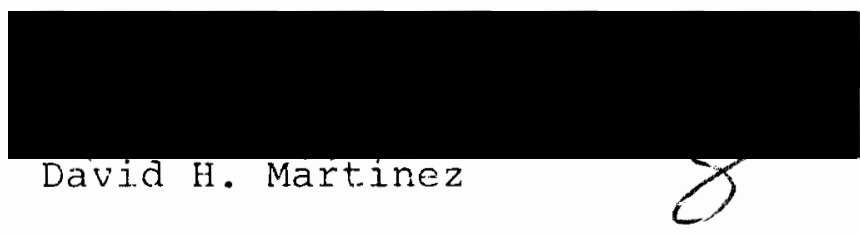

Many different versions of the original Token Test (De Renzi and Vignolo, 1962) have been available to speechlanguage pathologists as a language assessment tool with various populations. The most recently adapted version of the Token Test is the Token Test Eor Children developed by Disimoni (1978) as a measure to detect subtle receptive language abilities in children.

The purpose of this study was to determine if a significant difference existed between reading disabled and 
normal readers on syntactic and memory abilities on the Token Test for Children and if a difference existed between reading disabled students in grades $3-6$ and dyslexic adolescents in grades $7-12$ from the Whitehouse (1983) study.

Twenty-five reading disabled subjects and twentyfive normal readers from grades 3 - 6 participated in this study. Each subject met the criteria for the California Achievement Test scores (reading disabled, scores of 40 NCE or below; normal readers, scores within normal range), receptive vocabulary within one stardard deviation, normal unilateral hearing, and a monoingual background. The Token Test for Children was administered individually and the results were scored and analyzed using Whitehouse's (1983) scoring system.

Subtest means and standard deviations, syntactic errors and memory errors, t-values, z-values, and percent scores were compiled. Several t-tests and $z$-tests were conducted to determine if a difference existed between the mean number of syntactic and memory exrors for both groups. The t-test results indicated a statistically significant difference on the mean muber of syrutactic and memory errors between the reading disabled and normal readers on the Token Test for children beyond the 0.05 level of confidence. As anticipated, the reading disabled subjects made errors on the entire test, with more syntactic and memory errors on Part $V$. Further analysis of the test 
results showed that Part $V$, which increases in length and becomes more grammatically complex resulted with the highest number of errors for both groups. It was also found that no significant difference was evident among grade levels for the reading disabled in grades 3 - 6 to dyslexic adolescents in grades 7 - 12 from the Whitehouse (1983) study. The results suggest that difficulties in language abilities continue into adolescence.

The overall performance of the readjng disabled subjects revealed a higher number of syntactic and memory errors on the Token Test for Chilaren in comparison with the normal reading group. The test results, particularly Parts IV and $V$, suggest that the Token Test for Children may help to identify subtle receptive language deficits in reading disabled children. Further research should investigate the language abilities in the areas of syntax and memory in children with learning disabilities on an age continuum. 


\section{THE PERFORMANCE OF READING DISABLED 3rd to 6th GRADERS ON THE TOKEN TEST FOR CHILDREN}

by

JANE J. KIHARA

A thesis submitted in partial fulfillment of the requirements for the degree of

MASTER OF SCIENCE IN SPEECH COMMUNICATION

$$
\text { with an emphasis in }
$$

SPEECH-LANGUAGE PATHOLOGY

Portland State University

1986 
TO THE OFFICE OF GRADUATE STUDIES AND RESEARCH:

The members of the Committee approve the thesis of Jane J. Kihara presented June 6, 1986.

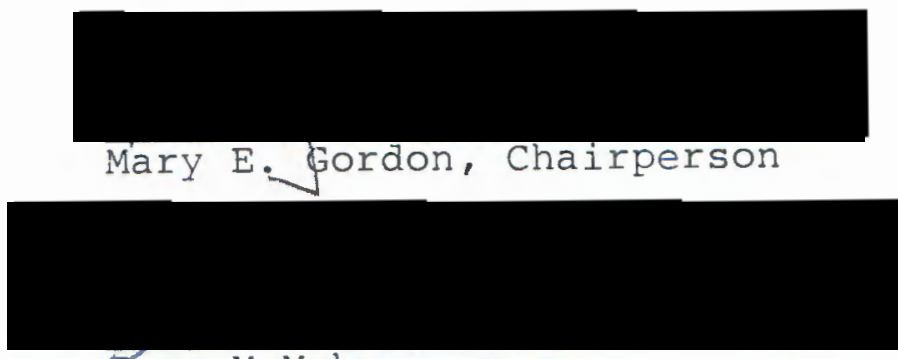

Zoan McMahon

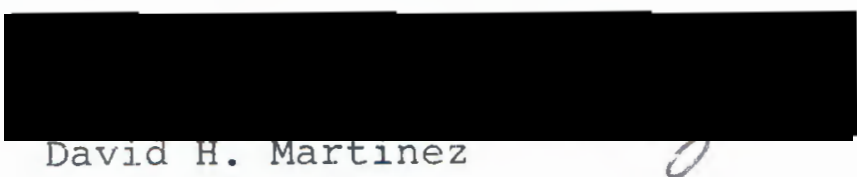

APPROVED :

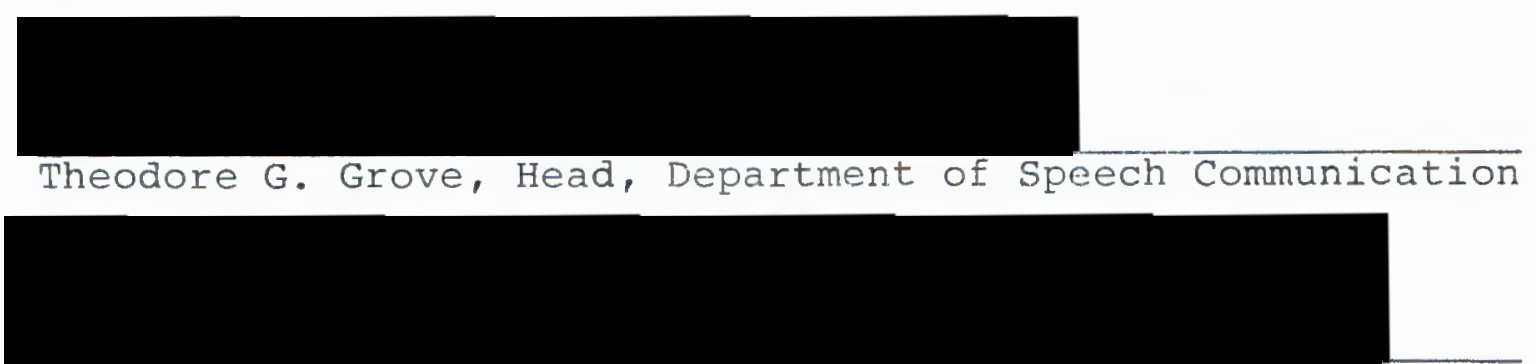

Bernard Ross, Dean, Graduate Studies and Research 


\section{ACKNOWLEDGEMENTS}

I wish to extend my sincerest thank you to Mary Gordon who most unselfishly shared with me her time, knowledge and expertise. Thank you Mary for your constant guidance, support and encouragement as my thesis advisor during this project. It has been through your feedback and nudging that I inched forward, even if I encountered a few steps backwards too. Thanks again for your professional guidance and teachings.

I am also grateful to members of my committee, Joan McMahon and Dr. David Martinez for your insightful suggestions on my thesis and words of encouragement.

A heartful thanks goes to the personnel. including the Speech-Language Pathologists and Reading specialists, parents, and students at Candy Lane, King and John McLoughlin Elementary schools. A special appreciation goes to Karen Jenkins who helped me start my initial stacjes of testing in the schools.

I want to thank Dr. Craig Magwire for his guided assistance and help in interpolatjng trie statistical data and making it a fun process.

To my fellow colleagues, Amy, Reggy, Stephanie, Kelly, Alissa, Jim, Pam, Carol and Vicki goes a big hug for the buddy support system you all shared. I owe a special thank you to Amy who has been a wonderful, helpful and encouraging 
friend. It has been a joy sharing our educational experience together. We made it, Amy!

Special thanks are due to my friends Ray and Kikuko and to my long-distance friends, Kathie, Jenny, Loyd and Kent for your kind words of encouragement. I extend my sincere appreciation to my pal kent for your thoughtfulness and support during this project.

Most of all, to my family, a genuine "mahalo" for your love, support and encouragement during my educational experience in graduate school. To my dad, I thank you for your words of wisdom, "gumbatte" philosophy and believing in me. To my mom, I thank you for your caring and understanding, and your love that lifted my gray days and added that extra bit of sunshine to help me keep on going. And to my brothers Les and Wayne, I extend my thanks to you both for understanding and allowing me to pursue my education away from home. Lastly, thank you, Lord. 
LIST OF TABLES . . . . . . . . . . . . . . vii LIST OF FIGURES . . . . . . . . . . . . . . . . ix

\section{CHAPTER}

I INTRODUCTION AND STATEMENT OF PURPOSE 1

Introduction . . . . . . . . . . . . 1

Statement of Purpose . . . . . . . 3

II REVIEW OF THE LITERATURE 4

The Nature of Reading visability . . . 4 Incidence of Reading Disabilities. 5 Theories of Reading Disability . . 6 Types of Reading Disability. . . . 8

Reading Disability and Language . . . 9 Reading and Syntax... . . . 10

Memory and Language . . . . . . . 11

Developmental Changes in the Linguistic Performance with Reading Disability ll

Assessment of Linguistic Factors in Early Reading . . . . . . . . 14

The Token Test: A Review of Studies.. 15

A Review of the Token Test for Children . . . . . . . . 17

III METHODS AND PROCEDURES 22

Subjects ............... . . 22

Instrumentation ........... . 24

Testing Environment . . . . . . . 25

Procedures ............ . 25

Screening . . . . . . . . . 25 
TABLE OF CONTENTS

CHAPTER

PAGE

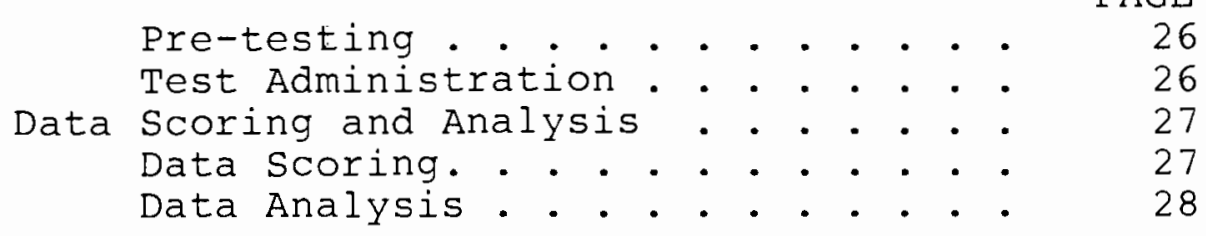

IV

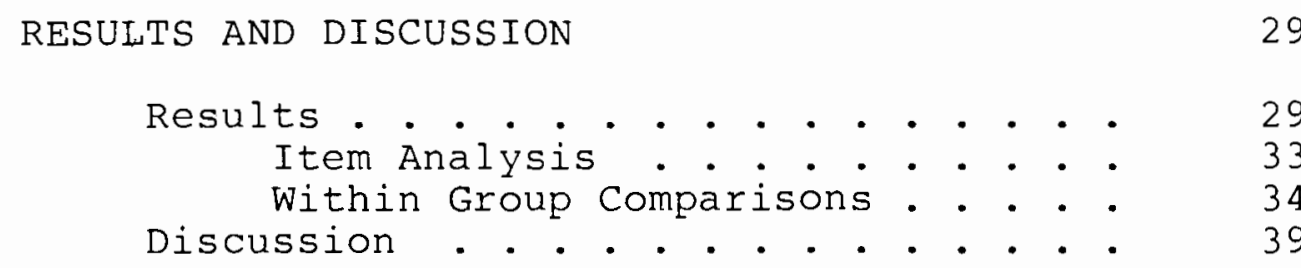

V SUMMARY AND IMPLICATIONS

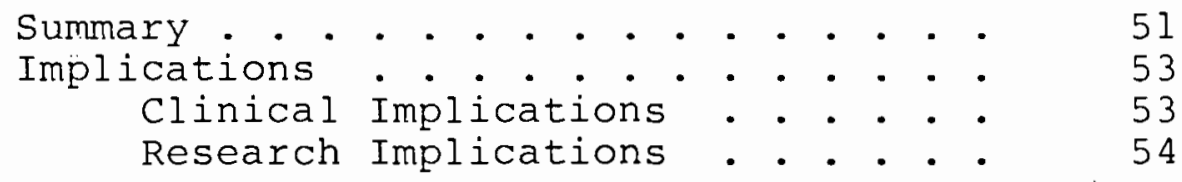

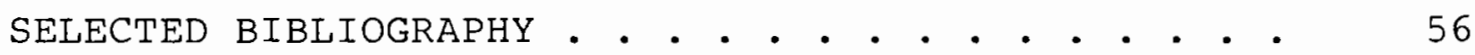

APPENDIX . . . . . . . . . . . . . . . . . 61 
LIST OF TABLES

TABLE

PAGE

I Representative Commands from the Token Test

for Children............ . . 18

II Number of Subjects from Each Group within

Each Grade Level . . . . . . . . . . 23

III Mean Scores, $\underline{t}$-values, and $\underline{z}$-values for

Reading Disabled and Normal Readers for the

Entire Test on Syntactic Errors, Memory

Errors and Syntactic and Memory Errors

Combined . . . . . . . . . . . 30

IV Mean Scores, $t$-values, and $z$-values for

Reading Dišabled and Normal Readers for

Part $V$ on Syntactic Errors, Memory Errors

and Syntactic and Memory Errors Combined.

$\checkmark$ Percent of Children who Erred on Each Item

In Subtest $V$ for Reading Disabled and

Normal Readers..... . . . . . . . .

VI ANOVA Summary Table for Comparing Means of

Syntactic Errors Distributed by Grade

Levels Within the Reading Disabled Group

for Part V. . . . . . . . . . 35

VII ANOVA Summary Table for Comparing Means of

Memory Errors Distributed by Grade Levels

Within the Reading Disabled Group for Part

VIII ANOVA Summary Table for Comparing Means of

Syntactic Errors Distributed by Grade

Levels Within the Normal Readers Group

for Part V . . . . . . . . . . . . .

IX ANOVA Summary Table for Comparing Means of

Memory Errors Distributed by Grade Levels

Within the Normal Readers Group for Part

$\mathrm{X}$ Mean Number of Errors and Standard Deviations

XI ANOVA Summary Table for Comparing Means of

Syntactic and Memory Errors for Reading

Disabled in Grades $3-12$ for Part $V$. . . 
viii

\section{LIST OF TABLES (Continued)}

TABJ:E

PAGE

XII Means and Standard Deviations of Syntactic and Memory Errors from a Pooled Sample of Reading Disabled for Fach Grade Level For

Part V. . . . . . . . . . . . . . 39 


\section{LIST OF FIGURES}

FIGURE

PAGE

1. Arrangement of tokens for Parts I, III, V . . 19

2. Arrangement of tokens for Parts II and IV . . 19

3. Memory and Syntactic Errors in Percent Scores for Reading Disabled and Normal Readers on Part IV............. . . 4 42

4. Memory and Syntactic Errors in Percent Scores for Reading Disabled and Normal Readers on Part $\mathrm{V}$. . . . . . . . . . . . 42 


\section{CHAPTER I}

\section{INTRODUCTION AND STATEMENT OF PURPOSE}

\section{Introduction}

Specific reading disabilities (SRD) is usually defined as an inability to read normally despite normal intelligence, intact senses, proper instructions, and normal motivation (Critchley, 1970; Meyers and Hammill, 1976). SRD commonly is apparent in combination with other impairments in areas such as memory, memory for sequence, left-right orientation, time orientation, body image, spelling and writing, calculation, motor coordination, and visual acuity. SRD does not result from mental retardation, emotional problems, sensory impairments, or inadequate teaching (Meyers and Hammill, 1976). According to Wiig and semel (1976) the results of more than thirty studies suggest that most reading disorders reflect syntactic and semantic deficits rather than auditory-perceptual abilities.

Studies have been conducted on the relationship between syntax and reading to assess the syntactic ability in groups of children who differ in their reading ability (Vogel, 1975). More recent research supports the contention that a syntactic impairment in both receptive and expressive 
language are marked deficits in children with reading disabilities (Whitehouse, 1983).

From the results of her study in which the Token Test (De Renzi and Vignolo, 1962) was administered to learning disabled subjects, Lapointe (1976) recognized that the Token Test may be a valuable tool in assessing syntactic abilities in adolescents. The Token Test, originally designed as a test of receptive language functions for aphasic patients, has been shown to be sensitive to subtle syntactic impairments in these patients (Poeckm, Orgass, Kerschensteiner, and Hartje, 1974) and other language impaired populations (Tallal, 1975). In a recent study, Whitehouse (1983) investigated the appropriateness of the Token Test as a means of evaluating language processing deficits in male adolescents with specific reading disabilities. The studies of Lapointe (1976) and whitehouse (1983) concluded that the Token Test, particularly Part V, is a useful tool for diagnosis of subtle receptive language disorders in learning disabled adolescents and dyslexic individuals.

Disimoni (1978) developed the Token Test for Children specifically for younger children. It is similar to the original version of the Token Test (De Renzj. and Vignolo, 1962 ) and has normative data for ages 3 - 12.5 years old. This test contains a minimum redundancy of commands and becomes increasingly difficult in length and complexity that may increase the load on memory and attention. The 
Token Test for Children may serve as a rapid screening device to provide a gross measurement of functional language adequacy and as an indicator for further need in testing lexicon and syntax (DiSimoni, 1978). In addition, this test also may be useful in identifying subtle receptive language deficits in children with SRD.

\section{Statement of Purpose}

The purpose of this study was to investigate the performances of normal readers and students with reading disabilities in grades $3-6$ on the Token Test for Children (DiSimoni, 1978). Specifically, this investigation sought to answer the following questions:

1) Is there a significant aifference of a) syntactic errors and b) memory errors between reading disabled and normally reading 3ra - 6th grade students as revealed by the Token Test for Children?

2) Is there a difference in syntactic and memory abilities when comparing the reacijing aisabled 3 6 grade students from the present study with the dyslexic adolescent 7 - 12 grade students from the Whitehouse (1983) study? 


\section{CHAPTER II}

\section{REVIEW OF THE LITERATURE}

In this review of the literature, the nature of reading disability, with emphasis on the linguistic context, will be discussed. In addition, research on the Token Test for Children (Disimoni, 1978) as a testing instrument in identifying deficient linguistic components in the language disordered population, including reading disabled children, will be reviewed.

\section{The Nature of Reading Disability}

The terms dyslexia, reading-disabied, reading impaired, developmental dyslexia, and poor readers are used interchangeably to describe children of at least average intelligence who read below age-appropriaie grade ievel, but do not demonstrate emotional disorders, gross sensory or neurological disorders, or experience ponr educational environments (Gross and Rothenberg, Is79). Dyslexia, or specific reading disability (SRD), was originally identified and studied primarily in aphasics as a loss or impairment in an individual's ability to read (Vogel, 1975). The deficit in reading skills was first described as congenital word blindness at the end of the 1.9th century and further described at the beginning of the 20 th century by Hinshel- 
wood (1917), a British opthalmologist. He identified dyslexia as a developmental defect or agenesis in the angular gyrus of the cerebral cortex, rather than an insult to the brain (Vogel, 1975). He reported that there exists an absence of any general intellectual or nonlinguistic defects in this disorder (Vogel, 1975).

Following Hinshelwood, Orton (1937) expanded the concept of developmental disorders in children to include not only reading, but also writing and speech problems. Orton believed that there was a delay in the process of establishing unilateral brain superiority. He also noted that there may be a hereditary factor involved in some cases (Vogel, 1975). Orton supported the notion that dyslexic children were experiencirg a developmental lag in acquiring all language skills.

\section{Incidence of Reading Disabilities}

According to research studies, SRD or dyslexia is more marked in males than in Eemales. Vogei (1975) reported that the ratio of males to females has ranged Erom 2:1 to 5:1. Theorists have suggested that possible reasons for a higher incidence in males may be due to sex-linked inheritance, greater vulnerability of the maje sex, and the expectations of important and influentiai people in the child's environment (Vogel, 1975). The occurrence of developmental dyslexia in the general population is about 5 to 10 percent according to Critchley (1970). Rabinovitch (1968) estimated 
that at least 10 percent of all children in the United States are handicapped by reading incompetence before they reach the seventh grade. Briefly, reading incompetence is defined as a significant discrepancy between actual and expected reading levels for mental age equivalence.

Theories of Reading Disability

The study of the nature of dyslexia has received much impetus in the United States since Orton's work (1937) suggested that faulty or incomplete dominance might be responsible for reading disability (Malatescha and Dougan, 1982). A major controversy in the field involves the question of the nature of dyslexia, whether it is a single problem or represents a group of disorders.

Over the years there have been many efforts to attribute reading disability to one particular cause. The most widely discussed hypothesis has been that of Orton (1937) who believed that sensory impulses are received simultaneously in both cerebral hemispheres and that memory traces are formed in each and are mirror images of each other (Harris, 1982). Thus if one hemisphere is more dominant, the memory traces in the other would be suppressed and clear perception would result. If cerebral dominance is incomplete, however, the control could alternate and there would be shifting and inconsistent perceptions, resulting in many errors of the reversal types (Harris, 1982). Such reversal types include "saw" for "was" and "big" for "dig". 
Still there are others who sought reasons to the cause of reading disablity. Among those were Levinson (1980) who stated that reading disability is produced by the abnormal functioning of the cerebellum and the semicircular canals of the inner ear. Delacato (1968) attributed learning difficulties to immaturity in the brain below the cortical level and recommended treatment to exercise hand and eye dominance, creeping, and sleeping in a specific position. Bender (1957) stressed the idea of maturational lag, which implied the slow development of specific brain centers involved in reading while the rest of the brain developed normally. Frostig (1972) emphasized the importance of visual perception ơfficulties and suggested the treatment of the learring difficuities by the training of visual perception skills. Vellutino (1979) attributed all reading disabilities to generalized language deficits in visual perception, language or verbal processing. Cruikshank (1968) and Kephart (1960) viewed reading disorders as a form of learning disability attributed to poor perceptual-motor integration. Hermann (1959) favored the visual-spatial dysfunction, but suggested that it has a genetic predispositicn. Marshali and Newcombe (1973) have suggested that dysiexia in acilts may result from difficulties in sound-letter associations or from syntacticsemantic deficits. More recent studies have indicated an increasing awareness of the cognitive and linguistic processing deficits with learning disabled children and the 
relationship of these deficits to reading difficulties (Semel and Wiig, 1975; Vogel, 1974).

\section{Types of Reading Disability}

There are also different types of reading disabilities which have been described in the literature. A number of investigators divided dyslexia into visual and auditory types. Malatesha and Dougan (1982) stated that generally, auditory dyslexics appear to have difficulty in synthesizing sounds into words. This would include the language disorder group of reading disabled children (Kinsbourne and Warrington, 1966), the auditory-linguistic group (Pirozzolo, 1979), the linguistic or syntactic-semantic group (Bakker, 1979), and the auditory types (Johnson and Myklebust, 1967). In contrast, the visual dyslexics (Bakker, 1979; Johnson and Myklebust, 1967; Pirozzolo, 1979) are noted to have visual discrimination and related visual perceptual problems. Marshall and Newcombe (1973) supported the existence of three types of dyslexia 1) pure, visual dyslexia 2) surface dyslexia 3) semantic (deep) dyslexia all based on data from adults with acquired brain iesions. The pure, visual dyslexia is characterized by letter confusion (e.g., "b" for "d") and sequencing errcrs (e.g.. "saw" for "was"). surface dyslexia is characterized by difficulty in using correct grapheme-phoneme assocjations. Some of the difficulties occur on consonants/e.g., s,f,k,g,p,r/ whose phonemic value depends on the graphemic context. Semantic dyslexia is characterized by word substitutions (e.g., 
"speak" for "talk"), derivational errors (e.g., "hot" for "heat") and nominalization of base verbs (e.g., "entertainment" for "entertain") (Marshall and Newcombe, 1973). However, Marshall and Newcombe (1973) are cautious in inferring relationships between disorders of reading and language. They concluded by saying "our sole claim about the relationship of reading to other aspects of language has been that 'visual' dyslexia may occur in isolation and that 'deep' dyslexia does not occur without other aphasic features being present". With this plethora of subtypes of reading disability, a continued disagreement exists among researchers as to the nature and etiology of dyslexia. Malatesha and Dougan (1982) proposed that one of the reasons is due to the failure to recognize the possibility that dyslexia is actually a group of disorders and not a single isolated syndrome. They further stated that there exists an impressive amount of data that support the notion of heterogeneity of dyslexia.

\section{Reading Disability and Language}

Studies have suggested that the difficulties the reading disabled population have in language tasks include wordfinding difficulties, imprecise articulation, primitive syntax, poor verbal comprehension and expression (Kinsborne and Warrington, 1966; Rabinovitch and Ingram, 1968). Other studies have indicated evidence of the reading disabled having difficulty in processing syntactic information. In their expressive language, reading disabled children tend 
to use less complex utterances and types of grammatical structures (Fry, Johnson, Muehl, 1970). In addition, they also have difficulty in using morphological markers that indicate the possessive, verb tense or plural forms (Wiig, Semel and Crouse, 1973). In their receptive language abilities, reading disabled children have difficulty comprehending complex syntactic structures (Menyuk and Looney, 1972). According to Wiig and Roach (1975), their performance is poorer as compared to normal readers when sentence structures violate syntactic convention in repetition tasks. More recently, studies have illustrated a relationship between reading disabilities and syntax, as reported below.

Reading and Sytnax

Briefly, syntax refers to the body of rules which governs the way words are arranged into sentences (Chomsky, 1957). The influence of Chomsky's theory of transformational generative grammar (Chomsky, 1957, 1965) helped to set a model in recent studies on how a child learns to combine words to form grammatically acceptable sentences.

Reading experts have usually included vocabulary as a prerequisite for the success in learning to read. They also have recognized that syntax is important in both receptive and expressive language (Vogel, 1975). Rudel (1966, 1968) found that a child's reading comprehension and vocabulary correlate significantly with the control of morphology and syntax. She reported that reading comprehension signifi- 
cantly increases in first and second graders when the emphasis was given to meaning relationships hetween key structural elements within and between sentences (Vogel, 1975 ).

\section{Memory and Language}

One of the most important factors in the skilled use of language depends on memory, both long-term and short-term memory. The ability to remember aids processing and understanding of the spoken message (wiig and Semel, 1980). As stated by Chalfant and Scheffelin (1969), short-term memory is usually defined as recal. within seconds, whereas longterm memory is the retention in a matter of hours. Miller (1967) states that one of the most important prerequisites for normal development of syntax is the ability to remember a series of words in the correct sequence. This ability helps the individual to abstract and internalize the syntactic structures of the language to which he is exposed. It has been found that iearring disabled chidren and adolescents consistently have short-term memory deficits which may show up as a limitation in tre number of units they can retain (Wiig and semel, 1980). Shus, when determining management programs for learning disabled children it is important to ascertain their abilities to follow directions and their memory recall abilities.

\section{Developmental Changes in the Iinguistic Performance with Reading Disability}


tinue to use language and reading as general constructs (Vellutino, 1978). However, few theories address the problem of developmental changes in the relationship of language development and reading acquisition (Fletcher, 1981 ; Gibson and Levin, 1975). Developmental change is important for research on reading disability because "studies using subjects at one age may identify deficits associated with reading disability which are different from those found at other ages" (Torgesen, 1975).

One current theory of reading disabilities (satz and Van Nostrand, 1973; Satz, Taylor, Friel and Fletcher, 1978) addresses the problem of developmental change. The theory postulates that reading disability represents behavioral changes of those skills underlying developmental immaturity of the central nervous system (Civs). As stated, the theory predicts that factors associated with processing written and phonological aspects will. contribute more to performance differences between the disabled and the normal reader in young children (ages 5-7) than for older children (ages 10 - 12) (Fletcher, Satz, Scholes, 1981). In the later phases of reading acquisition, there is more dependence on higher order lingilistic skills (e.g., syntactic and semantic strategies) that are necessary for comprehending meaning from groups of woras (Gibson and Levin, 1975). Thus, reading abilities are predicted to vary with chronological age on the basis of developmental changes in the acquisition of reading skills (Fletcher, Satz, and scholes, $1981)$. 
Fletcher, Satz, and Scholes (1981) reported that syntactic errors in expressive language and oral reading are related to age-dependent factors. However, studies concerned with more general syntactic comprehension skills have been ambiguous in the possible relationship of age dependence. This ambiguity has resulted from several sources. First, few studies have examined morphological and syntactic aspects of language in preschool children (age 5) prior to the measureable onset of reading achievement (age 7) (Fletcher, Satz, and Scholes, 1981). Bloom (1975) states that this earlier time period is when many of these linguistic skills go through primary development. Secondly, Torgesen (1975) and Satz and Fletcher (1980) reported that like much of the research on reading disabilities, the age variable has been poorly controlled. Children of different ages were often placed together in reading groups (Semel and Wiig, 1975). Third, Fletcher, Satz, and Scholes (1981) stated that measures used to assess syntactic comprehension require certain linguistic skills that may develop at different rates. For example, the Northwestern Syntax Screening Test used in many studies (Semel and Wiig, 1975; Vogel, 1975) not only requires comprehension of sentences syntactically, but also lexically. Fletcher, Satz, and Scholes (1981) further reported that comprehension problems could reflect difficulty in processing the syntactic structures or the major lexical items of the sentence. Finally, several studies have assessed language performance with a measure requiring the child to read. 
Fletcher, Satz, and Scholes (1981) stated that while these studies are important, a variety of linguistic and nonlinguistic problems may be related to reading disabilities, thus their conclusions regarding language skills and the role of reading failure may be confounded by these procedures.

\section{Assessment of Linguistic Factors in Early Reading}

Until recently, the most popular explanation of reading problems focused on deficits in visual perception and perceptual-motor skills (Blachman, 1983). Test batteries emphasized perceptual-motor training; however, there is now extensive documentation in the literature of the importance of language-based skills in reading achievement (Liberman, 1982; Liberman and Shankweiler, 1979; Perfetti and Lesgold, 1979).

Blachman's study (1983) used the McCarthy Scales of Children's Abilities (MSCA) and the Reading Related Language Measures (RRLM) of segmentation, rhyming, and rapid automatized naming as predictors of kindergarten and first grade reading. She suggested that screening instruments should include language tests that are related to early reading acquisition. More specifically, she suggested that screening should include a measure of language analysis skill, rapid naming, and a test that is sensitive to differences in verbal short-term memory. Blachman (1983) further stated a need for more basic research in the area of language and its relationship to reading acquisition and also, 
more longitudinal research that examines the reading error patterns of children.

The next section will specifically review the Token Test (DeRenzi and Vignolo, 1962) as a possible tool for assessing linguistic factors of reading achievement.

\section{The Token Test: A Review of Studies}

The Token Test is a test of receptive language functions originally developed for aphasic patients by DeRenzi and Vignolo (1962). More recently, this test has been considered as a useful tool in the identification of language/learning deficits in adolescents (Lapointe,1976). This test has been shown to be sensitive to subtle syntactic impairments in aphasic patients (Poeckm, Orgass, Kerschensteiner, and Hartje, j.974) and other language impaired populations (Tallal, 1975].

The original Token Test (DeRenzi. and Vignolo, 1962) was designed to measure the processing of verbal directions of increasing length and complexity (Wiig and Semel, 1976). The test consists of 5 parts with a series of commands requiring the subject to manipulate tokens of various colors, shapes, and sizes. There are 20 tokens of 5 colors, 2 shapes, and 2 sizes. In parts I. - IV, commands are of verb-object format and increase in length from 4 to 10 words. There are 10 commands in parts I - IV and 22 commands in part $V$; which introduces different verb phrase and noun phrase structures. The verb "touch" is used throughout the 4 parts, but the noun phrase objects increase 
in length for each part. Examples of noun phrase objects includes: "Touch the red circle", "Touch the small yellow circle", and "Touch the yellow circle and the red square". Part $\mathrm{V}$ of the Token Test introduces the most syntactic and semantic variety (Whitaker and Whitaker, 1979).

Wiig, Lapointe, and Semel (1375) investigated the relationship between auditory language processes and oral language production abilities of adolescents with language disabilities. They administered a number of language processing and production tests and one of the findings indicated that the performance on the Token Test correlated positively with measures of verbal cognitive abilities, the Wechsler Intelligence Scale for children (WISC) Verbal IQ and with measures of expressive syntactic abilities of the Northwestern Syntax Screening Test (NSST).

Another study by Cartwright and Lass (1974) compared the scores of the Token Test and scores on the NSST (Lee, 1969 ) and confirmed a significant positive correlation between the two. The childrer who performed well on the Token Test also did weil on the NSST, and those who scored low on the Token Test also performed with low scores on the NSST. This significant correlation between the Token Test and the NSST indicates that both tests appear to be measuring similar receptive language characteristics. In addition, these findings provide support for the validity of the Token Test as an effective measure of receptive language. In Lapointe's (1976) study of learning disabled and normal adolescents performance on the Token Test, the re- 
sults indicate that language processing deficits are not present in all of the learning disabled in the study. However, the scores did reveal that part $\mathrm{V}$ of the test had a higher number of errors than any other subtest for both groups. In another study, whitehouse (1983) administered the Token Test to a specific reading disability group of adolescents to determine whether syntactic deficits account for poor performance on the test. Results of this study indicated that there is a correlation between syntactic complexity and reading disability.

\section{A Review of the Token Test for Children}

DiSimoni (1978) developed a screening test of language called the Token Test for Children. This modified version of the original Token Test (DeRenzi and Vignolo, 1962) "provides a gross measurement of functional language adequacy in the semantic sense, and as an indicator of the need for further testing of lexicon and syntax" (Disimoni, 1978). The test contains a minimum redundancy of commands and becomes increasingly difficult in length and complexity that may increase the load on memory and attention. The test measures a child's ability to aerive knowledge from what is said to him or her; thus, it yields a general comprehension score. The test construction is similar to the original Token Test; consisting of five parts, each increasing in length and complexity. The test consists of 20 tokens of 2 different sizes (large and small), 2 different shapes (circles and squares); and 5 different colors 
(red, blue, green, yellow and white). The tokens are placed in front of the child in a pre-determined order and the examiner gives a variety of oral commands to manipulate the tokens. The test consists of a total of 61 commands. There are 10 commands in each of the first four parts, and 21 commands in part $V$. Only 10 tokens, the large circles and squares are used in parts I, III, and $V$ of the test, while parts II and IV use all 20 tokens. Figures 1 and 2 shows the arrangement of the tokens used in the test.

The commands in parts I - IV are expressed in simple syntactic form (verb and object), with the word "touch" being the constant verb. In part $V$, the sentence structure becomes more complex grammatically and syntactically, incorporating conjunctions, prepositions, and articles. Representative commands are shown in Table I.

\section{TABLE I}

REPRESENTATIVE COMMANDS FROM THE TOKEN TEST FOR CHILDREN

Part

Command

Touch the red circle.

II Touch the small yellow circle.

III Touch the yellow circle and the red square.

IV Touch the small yellow circle and the large green square.

$V$ This part has more complex grammatical and syntactical structures, with several conjunctions, prepositions, and articles introduced. Example: Put the green square away from the yellow circle. 


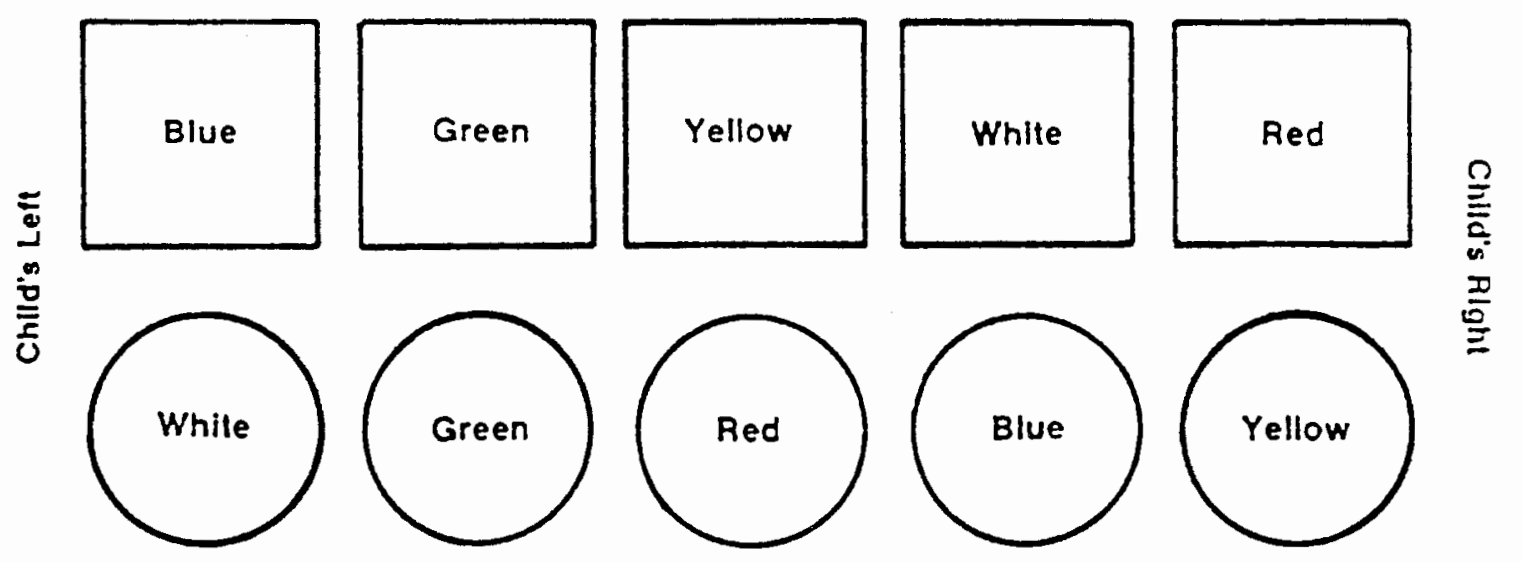

Figure 1. Arrangement of tokens for Parts I, III, V.

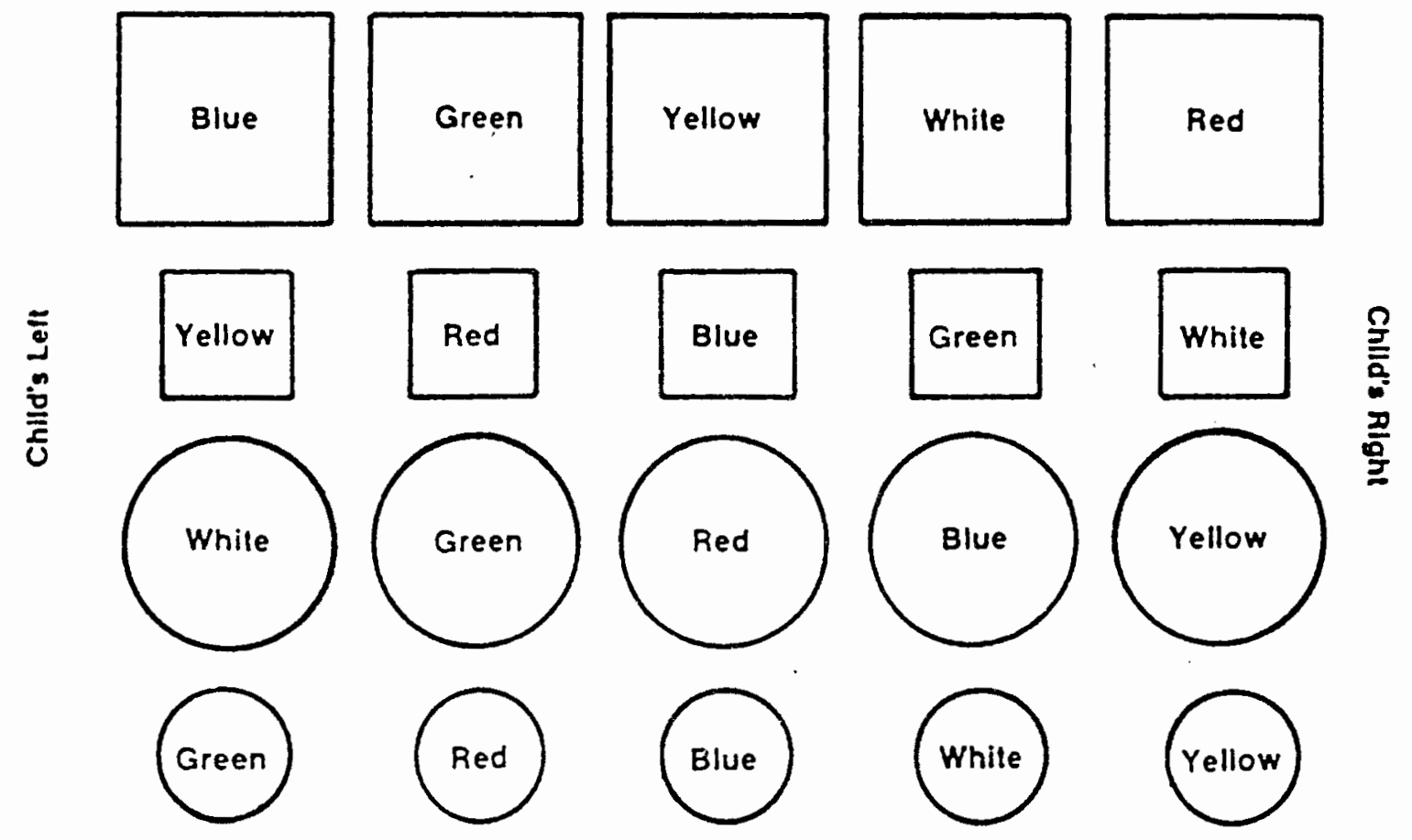

Figure 2. Arrangement of tokens for Parts I I and IV. 
The Token Test for Children has normative data for children ages 3 to 12.5 years. Standardization was based on 1,304 children ages 3 to 12.5 years old. All were native speakers of English, spoke a general American dialect, and none had any known language problems. Although Disimoni (1978) provides no reliability or validity coefficients for the Token Test for Children, based on data from the original Token Test (DeRenzi and Vignolo, 1962) and the Revised Token Test (McNeil and Prescott, 1978), the reliability is adequate at 0.92 and 0.90 respectively. The test manual reports the data in half-year age norms and in school grade norms in reference to means, stardard deviations, and standard scores. The standard score is interpreted as to how well a child performs on the test in relation to children of similar ages or school grades in verbal listening ability.

This last section has reviewed the recently modified version of the original Token Test; the Token Test for Children (Disimoni, 1978) which is regarded as equally valid as the Token Test by DeRenzi and Vignolo (1962). The Token Test for Chilaren offers a quick but specific linguistic assessment of determining whether a dyslexic child's reading disability stems from a prinary linguistic deficit. Lipa (1983) states the reading disability child has a unique problem associated with language processing and needs a program based on his or her language processing strategies; thus, the Token Test for Children may suggest further testing of linguistic weaknesses that may offer 
better understanding for a language remediation program. 


\section{METHODS AND PROCEDURES}

The following is a discussion of the methods utilized in this present investigation. The selection of subjects, test instrument, test environment, procedures, and data analysis are described.

\section{Subjects}

Fifty subjects ranging in age from nine to twelve years were selected from regular classrooms and caseloads of speech-language pathologists and reading specialists in the Candy Lane Elementary, King Elementary, and John McLoughlin Elementary schools in Oregon City, Oregon. The subjects comprised two groups: 1) the experimental group containing twenty-five students with reading disabilities and 2 ) the control group containing twenty-five normal readers. The normal readers group matched the reading disability group for each grade level. see Table II for a distribution of subjects.

In addition to grade level requirements, the subjects met the following selection criteria:

1. All subjects in the normal reading group and the reading disability group were administered the California Achievenert Test (CAT) at the beginning of each school year; 
NUMBER OF SUBJECTS FROM EACH GROUP WITHIN EACH GRADE LEVEL

Number of Subjects

$\begin{array}{lcccr}\text { Group } & 3 \text { rd } & 4 \text { th } & 5 \text { th } & 6 \text { th } \\ \text { Normal Readers } & 6 & 6 & 9 & 4 \\ \text { Reading Disability } & 6 & 6 & 9 & 4\end{array}$

2. Subjects were included in the reading disability group if their scores were below 40 on the National Curve Equivalence (NCE) on the California Achievement Test and they scored one year below grade level on the standardized reading test appropriate for each grade level. For subjects in grades 2 - 5, the Stanford Diagnostic Reading Test is administered and for subjects in grade 6 , the Gates-MacGinitie Reading Test js administered;

3. Subjects in the normal reading group were drawn from grades $3-6$ who performed at appropriate grade level on the California Achievement Test;

4. Subjects were from monolingual, Standard American English speaking families;

5. Subjects had normal hearing: sensitivity, determined by an unilateral audiometric screening at 20 dB HL for the frequencies of 500, 1000, 2000, and $4000 \mathrm{~Hz}$;

6. Subjects had a receptive vocabulary age within one standard deviation for chronological age level, based on the Peabody Picture Vocabulary Test- Revised (PPVT-R, Dunn, 1979); and

7. Subjects had no noted or suspected unusual developmental, social, or behavioral histories and other handicapping conditions such as cerebral palsy, blindness, hearing impairment or autism, based on teacher report and investigator observation.

A parental permission form explaining the purpose of 
of the study was sent home with all $3-6$ graders enrolled in the Candy Lane Elementary, King Elementary and John McLoughlin Elementary schools (Appendix A). Those students who returned the signed parental permission forms were screened for participation in the study.

\section{Instrumentation}

A portable Beltone audiometer, ANSI 1969, was used for the audiometric screening.

The Peabody Picture Vocabulary Test-Revised (PPVT-R, Dunn, 1979) is a test to measure receptive vocabulary of individuals between the ages of 2 years, 6 months and 40 years. It consists of 2. forms, I and $M$, each with 175 stimulus pictures. The PPVT-R, form L was utilized to determine the children's receptive vocabulary ages as compared to their chronological ages.

The Token Test for Children (Disimoni, 1978) is a rapid and effective test to assess subtle receptive language dysfunction in children. This modification of the original Token Test (DeRenzi and Vignolo, 1962) consists of the same types of commands, each increasing in length and complexity. As mentioned previously no reliability studies have been conducted for this test. For this study the Token Test for Children is primarily used as an experimental device in identifying receptive language abilities in reading disabled children. The test materials include 20 tokens of two different sizes (large and small), two different shapes (circles and squares), and five 
different colors (red, blue, green, yellow, and white). The tokens are placed in front of the child in a predetermined order and the examiner gives a variety of oral commands to manipulate the tokens. See Appendix B for the test commands.

\section{Testing Environment}

During the administration of the PPVT-R and the Token Test for Children, both normal and reading disability subjects sat at a table in a chair to the left of the investigator in the clinic room (unless a visual field or unilateral hearing deficit dictated a right-sided seating arrangement for the subject), close enough to point, manipulate, and gesture at the tokens. During the hearing screening, the subjects were seated directly across from the investigator. In this manner, the audiometer was stationary and the PPVT-R was administered with adequate surface space.

\section{Procedures}

\section{Screening}

Student school records were reviewed and those students who met the CAT and reading test scores criteria were then given the parental permission forms. Returned parental permission forms were checked and those students who were permitted to participate in the study and met the monolingual criterion were selected for further screening. A pure-tone screening test (ANSI, 1969) and the PPVT-R, Form 
I were administered to each child. Results were immediately recorded on individual record forms. Fifty children, 25 normal readers and 25 reading disabled, who met all the screening and grade level criteria were chosen for inclusion in the study.

\section{$\underline{\text { Pre-testing }}$}

Before starting the formal test administration of the Token Test for children, the examiner determined that each subject could, without error, jdentify the colors, shapes, and sizes of the tokens. Each subject was given the opportunity to identify the tokens first, by expressive naming and if needed, secondiy, by receptive pointing. Those children who were unable to identify the tokens correctly by either tasks were not to be included in the study. All potential subjects passed the pre-testing tasks.

\section{Test Administration}

During both the pre-testing and experinental testing, the examiner sat to the right side of the subject being tested. All tests were adminjstejed individually and scored immediately following i response. The examiner explained to each subject that a series of commands would be presented to them. The surjects were instructed to wait until the complete command was presented before manipulating or gesturing to the tokens. The following instructions were presented to each chila:

"I am going to ask you to do different things with these (gesture at tokens). Listen very carefully because each direction can be said only once. Some of them will be easy and some will be harder to do. Are you ready?" 
All test commands were spoken clearly and with no emphasis or stress on any word. If the child asked the examiner to repeat a command, the examiner replied, "I can only say it once. Do what you think I said". If the child still does not attempt the task, the examiner said, "Let's go on to the next one".

\section{Data Scoring and Analysis}

\section{Data Scoring}

The responses by each individual on the Token Test for Children were marked correct (t) or incorrect (-). Each correct response has a value of one point for a total of 61 possible correct responses. An additional scoring system for errors represented by a list of memory errors, including size, color, and shape errors, and syntactic errors was utilized. This scoring system is similar to that used by Whitehouse (1983) and Noll and Randolph (1978). Errors were classified as memory errors if the subject correctly manipulated the token but used the wrong token. These would include color exrors (e.g., touching the little red circle instead of the ijtle green circie), size errors (e.g., touching the big green square instead of the little green square), and shape errors (e.g., touching the little green square instead of the little green circle). Errors were classified as syntactic errors if the subject used the correct tokens, but incorrectly manipulated them (e.g., putting the green square on top of the red circle instead of putting the red circle on top of the green square). 
The coding system from whitehouse (1983) study was used in recording the errors: S=syntactic error, $M S=$ memory for shape error, $M C=$ memory for color error, $M S Z=$ memory for size error, and $U=$ unclassified error.

\section{Data Analysis}

The results from the Token Test for Children for each subject's response were recorded and tabulated, then analyzed by $\underline{t}$-test statistics, $\underline{z}$-test statistics and ANOVA. The $\underline{t}$-test and $\underline{z}$-test statistics were used to investigate whether a difference existed between the mean number of errors for the two groups on syntactic and memory errors. The level of confidence for the $\underline{t}$-value and $\underline{z}$-values under each of the test condition was selected to be significant beyond the 0.05 level. Further data analysis was conducted using the ANOVA to determine if a difference existed within each group, i.e., reading disabled and normal readers, and between grade levels, i.e., grades $3-12$ for the reading disabled group on the Token Test for Children. 
CHAPTER IV

RESULTS AND DISCUSSION

\section{$\underline{\text { Results }}$}

This study sought to compare the performance of reading disabled students with normal readers in grades $3-6$ on the Token Test for Children. In addition, the performances of the reading disabled students in grades $3-6$ was compared to dyslexic adolescents in grades $7-12$ from the Whitehouse (1983) study. The results presented in this chapter include overall mean performance scores and standard deviations obtained by the reading disabled and normal readers, as well as an item analysis for Part $V$ of the Token Test for Children.

The first research question posed was: Is there a significant difference of a) syntactic errors and b) memory errors between reading disabled and normal readers in grades $3-6$ on the Token Test for Chilaren? The t-test statistic and $\underline{z}$-test statistic were used to compute the syntactic and memory errors for the entire test and for Part $\mathrm{V}$ for both groups, i.e., reading disabled and normal readers (See Tables III and IV). The z-test statistic was used for calculating the difference between the means for memory errors because the variances of the two samples 


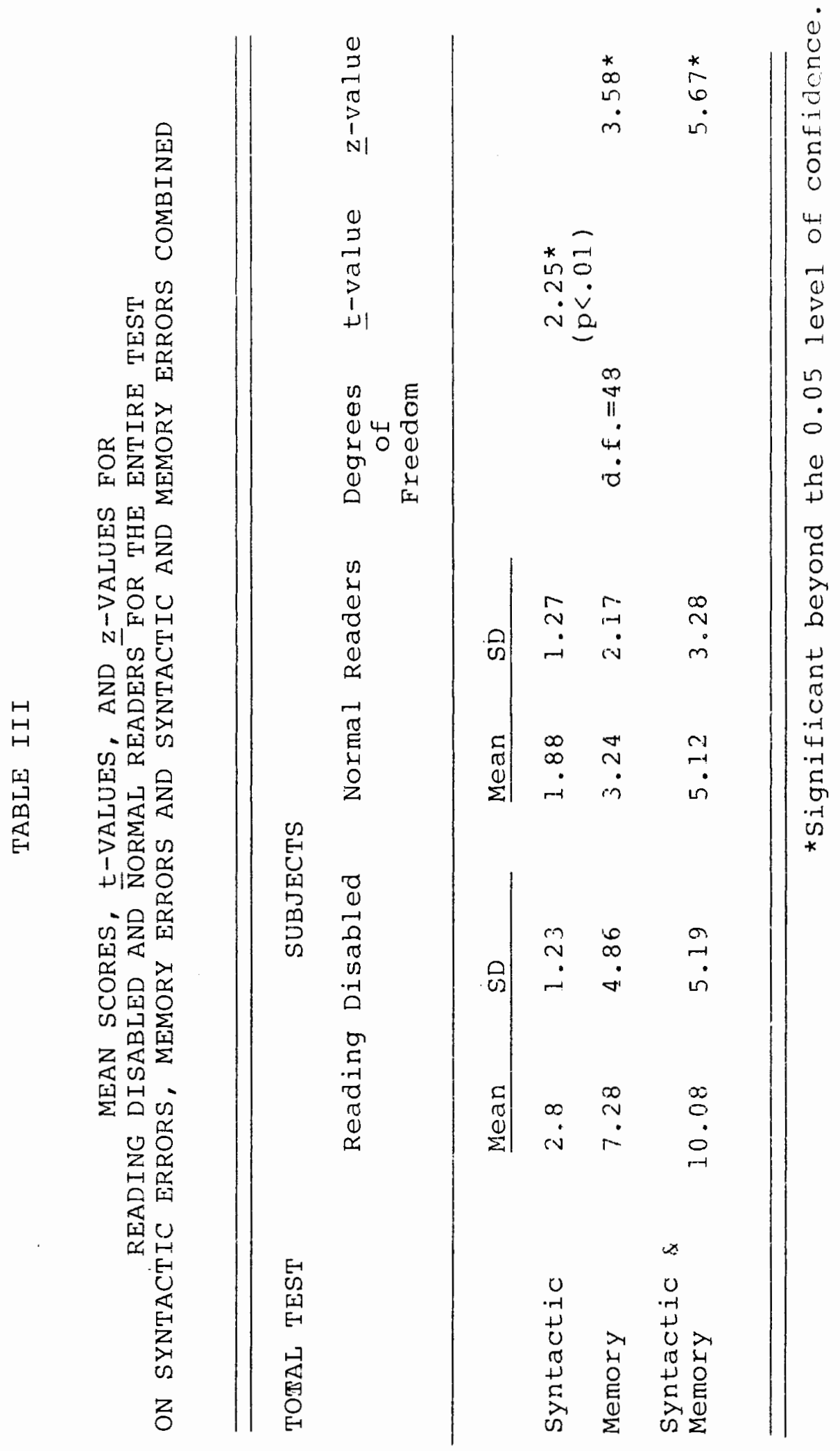




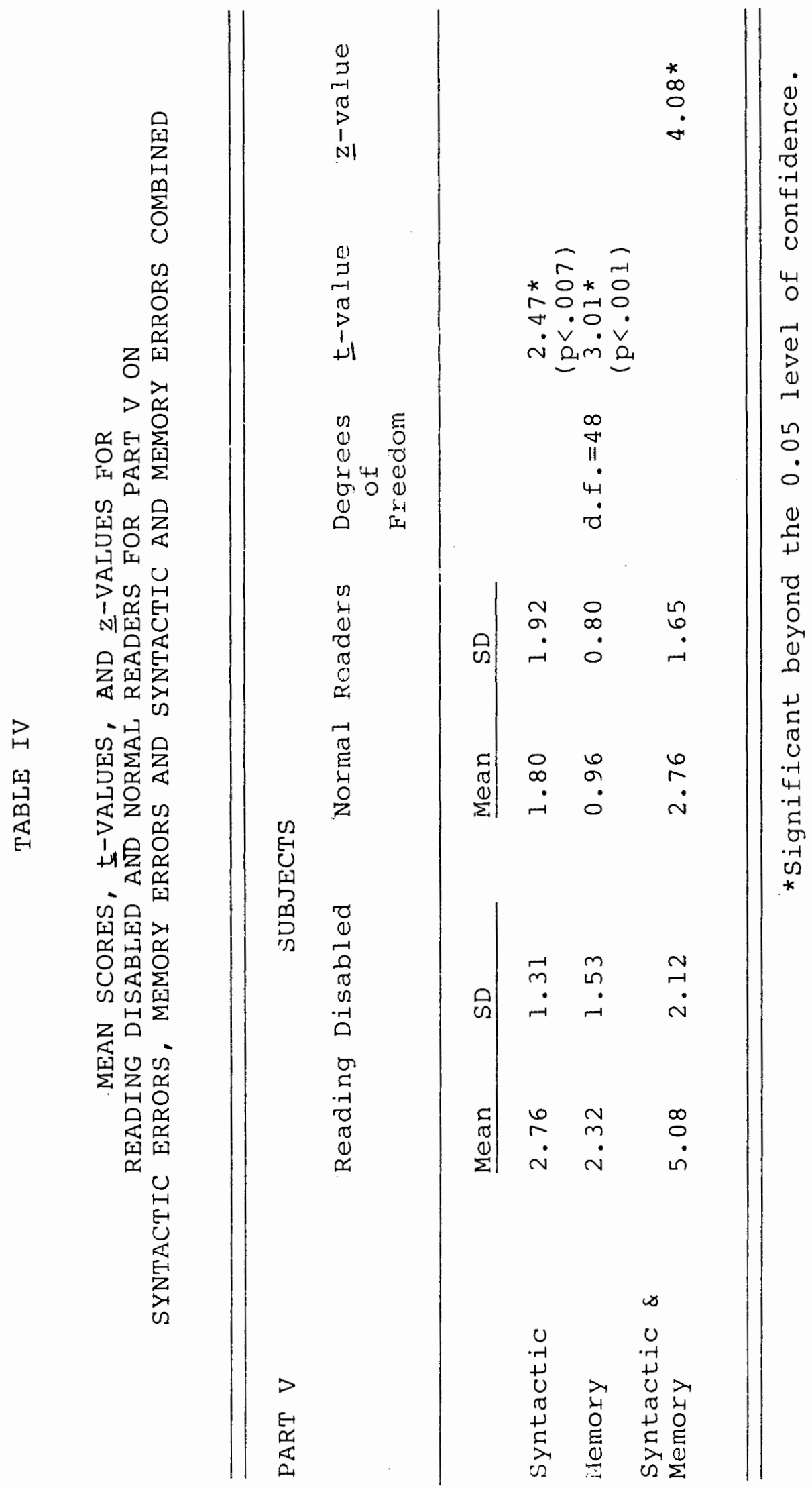


were not equal; thus, it was inappropriate to use the t-test statistic. Comparison of the two groups for memory errors for the entire test resulted in a significant $\underline{z}$-test value of 3.58 ( $p<.05)$, with the reading disabled group : showing more errors $(\overline{\mathrm{X}}=7.28)$ than the normal reading group $(\bar{X}=3.24)$. Comparison of the two groups for syntactic errors for the entire test resulted in a significant t-test value of 2.25 (p<.01), with the reading disabled. group showing more errors $(\bar{X}=2.8)$ than the normal reading group ( $\bar{X}=1.88)$. Similarly, comparison of the two groups for syntactic errors for Part $V$ resulted in a significant t-test value of 2.47 ( $\rho<.007)$, with the reading disabled group showing more errors $(\bar{X}=2.76)$ than the normal reading group $(\bar{x}=1.80)$. Comparison of the two groups for memory errors for part $V$ resulted in a significant t-test value of 3.01 ( $p<.001$ ) with the reading disabled group showing more errors $(\vec{X}=2.32)$ than the normal readers $(\bar{X}=$ $0.96)$.

Additional comparisons of the two groups were done for the total number of test errors, including both syntax and memory errors (Tables III and IV). A significant $\underline{z}$-test statistic of 5.67 resulted when comparing the mean number of errors on the ertise test. The mean number of total errors for the entire test for the reading disabled group $(\bar{x}=10.08)$ was greater than the mean number of total errors for the normal reading group $(\bar{x}=5.12)$. The z-test statistic for Part $V$ when comparing the two groups for total errors was 4.08, which is significant beyond the 0.05 level, with the 
reading disabled group showing more errors $(\bar{X}=5.08)$ than the normal readers $(\overline{\mathrm{X}}=2.76)$.

\section{Item Analysis}

For parts I through IV of the Token Test for Children the commands increase in length from one to six critical elements. Part $V$ uses a variety of linguistic components which become grammatically more complex. Table $\mathrm{V}$ presents a comparison of the percent of subjects who made syntactic and memory errors on each item in part $V$ for each group, i.e., the reading disabled and the normal readers. The two groups showed the same error patterns, although the reading disabled group had more overall errors.

The six items found to be most difficult for the normal reading group (items $3,5,13,18,19$, and 21) were also difficult for the reading disabled group and items $2,4,7,11,12,17$, and 20 appeared to have been additionally difficult for the reading disabled group. Overall, the reading disabled group had a greater percentage of error on 17 of the 2l. items than the normal reading group. Two items on which more errors were made by the normal readers were items 5 ("Touch the blue circle and the red square") and 13 ("Touch the squares slowly and the circles quickly").

A Pearson product moment coefficient of correlation $(r)$ was computed for the results of subtest $V$ items to determine the relationship between the reading disabled and the normal readers. The resultant $r$ was 0.72 , which shows a 
marked linear relationship between the two groups on Part V (Guilford, 1973).

\section{TABLE V}

PERCENT OF CHILDREN WHO ERRED ON EACH ITEM IN SUBTEST $V$ FOR READING DISABLED AND NORMAL READERS ( $N=25$ for each group)

\begin{tabular}{|c|c|c|c|c|}
\hline $\begin{array}{c}\text { Subtest } V \\
\text { item }\end{array}$ & $\begin{array}{l}\text { No. of Reading } \\
\text { Disabled who } \\
\text { Erred on Each } \\
\text { Item }\end{array}$ & $\%$ & $\begin{array}{l}\text { No. of Normal } \\
\text { Readers Who } \\
\text { Erred on Each } \\
\text { Item }\end{array}$ & $\frac{\circ}{\partial}$ \\
\hline $\begin{array}{r}1 \\
2 \\
3 \\
4 \\
* 5 \\
6 \\
7 \\
8 \\
9 \\
10 \\
11 \\
12 \\
* 13 \\
14 \\
15 \\
16 \\
17 \\
18 \\
19 \\
20 \\
21\end{array}$ & $\begin{array}{r}2 \\
7 \\
16 \\
11 \\
7 \\
4 \\
5 \\
4 \\
4 \\
0 \\
2 \\
4 \\
6 \\
3 \\
0 \\
5 \\
4 \\
9 \\
8 \\
6 \\
10 \\
117\end{array}$ & $\begin{array}{r}8.0 \\
28.0 \\
64.0 \\
44.0 \\
28.0 \\
16.0 \\
20.0 \\
16.0 \\
16.0 \\
0.0 \\
8.0 \\
16.0 \\
24.0 \\
12.0 \\
0.0 \\
20.0 \\
16.0 \\
36.0 \\
32.0 \\
24.0 \\
40.0\end{array}$ & $\begin{array}{r}1 \\
2 \\
12 \\
0 \\
9 \\
2 \\
1 \\
2 \\
3 \\
0 \\
0 \\
1 \\
8 \\
2 \\
0 \\
3 \\
1 \\
5 \\
6 \\
2 \\
9 \\
69\end{array}$ & $\begin{array}{r}4.0 \\
8.0 \\
48.0 \\
0.0 \\
36.0 \\
8.0 \\
4.0 \\
8.0 \\
12.0 \\
0.0 \\
0.0 \\
4.0 \\
32.0 \\
8.0 \\
0.0 \\
12.0 \\
4.0 \\
20.0 \\
24.0 \\
8.0 \\
36.0\end{array}$ \\
\hline
\end{tabular}

*Items in which normal readers had a greater percentage
of errors than the reading disabled subjects.

Within Group Comparisons

An analysis of variance for memory and syntactic errors was computed among the four grade levels $(6 \mathrm{th}, 5 \mathrm{th}$, 4 th, and $3 r d$ ) within each group. The results show no 
statistically significant differences $(p<.05)$ of the mean number of memory errors and syntactic errors among the four grade levels within each group (Tables VI, VII, VIII, and $(X)$.

TABLE VI

ANOVA SUMMARY TABLE FOR COMPARING MEANS OF SYNTACTIC ERRORS DISTRIBUTED BY GRADE LEVELS WITHIN THE

READING DISABLED GROUP FOR PART V

\begin{tabular}{lcccc}
\hline SOURCE & df & S.S & MS & F \\
\hline Grade levels & 3 & 3.45 & 1.15 & 0.54 (NS) \\
Error & 21 & 44.55 & 2.12 & \\
Total & 24 & 48.00 & & \\
\hline
\end{tabular}

TABLE VII

ANOVA SUMMARY TABLE FOR COMPARING MEANS OF MEMORY ERRORS DISTRIBUTED BY GRADE LEVELS WITHIN THE READING DISABLED GROUP FOR PART V

\begin{tabular}{lcccc}
\hline SOURCE & df & SS & MS & F \\
\hline $\begin{array}{l}\text { Memory errors } \\
\text { for grade levels }\end{array}$ & 3 & 1.47 & 0.49 & \\
Error & 21 & 97.97 & 4.67 & 0.105 (NS) \\
\hline Total & 24 & 99.44 & & \\
\hline
\end{tabular}

The nonsignificant F-value for memory errors was 0.105 
and for syntactic errors was 0.54 for the reading disabled group. The nonsignificant F-values for memory errors was 1.27 and for syntactic errors was 1.22 for the normal readers group.

\section{TABLE VIII}

ANOVA SUMMARY TAALE FOR COMPARING MEANS OF SYNTACTIC ERRORS DISTRIBUTED BY GRADE LEVELS WITHIN THE NORMAL READERS GROUP FOR PART V

\begin{tabular}{|c|c|c|c|c|}
\hline SOURCE & $d f$ & SS & MS & F \\
\hline $\begin{array}{l}\text { Syntactic ersors } \\
\text { for grade levels }\end{array}$ & 3 & 7.03 & 2.34 & \multirow{3}{*}{$1.22(\mathrm{NS})$} \\
\hline Error & 21 & 40.33 & 1.92 & \\
\hline Total & 24 & 47.36 & & \\
\hline
\end{tabular}

TABLE IX

ANOVA SUMMARY TABLE FOR COMPARING MEANS OF MEMORY ERRORS DISTRIBUTED BY GRADE LEVELS WITHIN THE NORMAL READERS GROUP FOR PART $V$

\begin{tabular}{lrrrr}
\hline \hline SOURCE & df & SS & MS & F \\
\hline $\begin{array}{l}\text { Memory errors } \\
\text { for grade levels }\end{array}$ & 3 & 3.53 & 1.18 & \\
Error & 21 & 19.43 & 0.93 & 1.27 (NS) \\
\hline Total & 24 & 22.96 & & \\
\hline
\end{tabular}


Additional information is displayed in Table $\mathrm{X}$ which presents the mean number of errors and standard deviations for grades 3 - 6 for the reading disabled and normal reader groups for Parts IV and $V$ of the Token Test for Children. The range of mean scores for parts $I V$ and $V$ was 1.4 to 4.83 and 4.0 to 5.16 , respectively for the reading disabled group. The range of mean number of errors for the normal readers was 0.89 to 2.67 for Part $I V$ and 2.0 to 3.5 for Part V.

TABLE X.

MEAN NUMBER OF ERRORS AND STANDARD DEVIATIONS

Reading Disabled

$\begin{array}{llllll}3 r d & 6 & 4.83 & 2.04 & 5.0 & 1.41 \\ 4 \text { th } & 6 & 2.8 & 1.47 & 5.16 & 2.43 \\ 5 \text { th } & 9 & 1.4 & 1.13 & 4.0 & 1.5 \\ 6 \text { th } & 4 & 3.5 & 1.91 & 4.75 & 2.5\end{array}$

Normal Readers

$\begin{array}{llllll}3 \text { rd } & 6 & 2.67 & 1.75 & 3.5 & 2.07 \\ 4 \text { th } & 6 & 2.16 & 1.17 & 3.17 & 2.04 \\ 5 \text { th } & 9 & 0.89 & 0.78 & 2.11 & 1.54 \\ 6 \text { th } & 4 & 1.25 & 1.89 & 2.0 & 1.83\end{array}$

The second research question posed was: Is there a difference in syntactic and memory abilities when comparing $3 r d$ - 6th grade reading disabled students and 7 th - 12 th grade dyslexic adolescents from the Whitehouse (1983) 
study? In Table XI, it can be seen that results from a pooled sample estimator indicate no difference in the mean number of errors on part $V$ of the Token rest for Children between the two experimental groups, i.e., the dyslexic adolescents in grades $7-? 2$ from the whitehouse (1983) study and the reading disabled students in grades 3 - 6 from the present study. The F-value for the pooled sample was 0.493 which is not significant at the 0.05 level of confidence. In the whicehouse (1983) study, the dyslexic adolescents had a greater overall error rate $(\bar{X}=0.068)$ than the normal readers $(\bar{x}=0.034)$ for grades $7-12$.

TABDE Y.I

ANOVA SUMMARY TABLE FOR COMPARJNG MEANS OF SYIJTACTIC AND MEMORY ERRORS FOR READING DISABLED IN

GRADES 3 - 12 FOR PART V

\begin{tabular}{lcccc}
\hline SOURCE & df & SS & MS & F \\
\hline Grade levels & 6 & 17.29 & 1.88 & $0.493(\mathrm{NS})$ \\
Error & 60 & 27.61 & 3.81 & \\
\hline Total & 66 & 228.909 & & \\
\hline
\end{tabular}

Table XII illustrates the means anä standard deviations of syntactic and memory ercors Erom a pooled sample of reading disabled students in grzdes 3 - 12, including white- 
house (1983) dyslexic adolescents and subjects from this present study for Part $V$ of the Token Test for Children. Generally, students in the higher grade levels had lower mean scores than those in the lower grade levels, although this pattern was not statistically significant.

TABLE XII

MEANS AND STANDARD DEVIATIONS OF SYNTACTIC AND MEMORY ERRORS FROM A POOLED SAMPLE OF READING DISABLED FOR EACH GRADE LEVEL FOR PART $V$

\begin{tabular}{cccc} 
Grades & $N$ & Mean & SD \\
\hline $12-11$ & 15 & 3.00 & 2.42 \\
$10-9$ & 15 & 3.80 & 1.37 \\
$8-7$ & 12 & 3.75 & 1.22 \\
6 & 4 & 4.75 & 2.50 \\
5 & 9 & 4.00 & 1.50 \\
4 & 6 & 5.16 & 2.43 \\
3 & 6 & 5.00 & 1.41
\end{tabular}

\section{Discussion}

The results of this study demonstrated a statistically significant difference in the performance between reading disabled and normal readers on syntactic and memory errors. The total test results of this study support the whitehouse (1983) and Lapointe (1976) studies for using the Token Test 
as an instrument for measuring subtle receptive language abilities in learning disabled individuals. The following paragraphs will include a discussion of the total test results, as well as specific results on part $V$ made by the reading disabled group and normal readers. In addition, within group comparisons among grade levels on syntactic and memory errors will be included.

Due to the relatively low error rate made on parts I and II of the Token Test for chilaren by both groups, these two parts will not be included in the remajnder of the discussion. However, a brief comment concerning a moaification of test administration procedure wil1 be addressea. Iri short, since both groups had low exror rates on parts I and II, this investigator suggests it is feasible to shorten the test administration time by administering only parts III - V after a pretest of color: shape and size identifi-cation is conducted.

An overall analysis of the total test scores for the Token Test for Children show that as the test increased in length ano complexity for each part ( I - V), the error rates increased for both groups (Appendices $C$ and $\Gamma$ ). However, the reading disabled group made significantly more errors, including botn syntactic ard meriory errors, than the normal readers (Appendix F). It can be seen that as more components (shape, size, and color) were added in Farts I - IV, the reading disabled group made more errors, indicating that more components increased the difficulty which may reflect the increasing load on memory and atten- 
tion (Lapointe, 1976). Furthermore, the reading disabled group made a greater number of syntactic errors $(\bar{X}=2.76)$ specifically on part $V$ than the normal readers $(\vec{X}=1.80)$. According to the conclusions from the studies of Whitehouse (1983) and Japointe (1976), poor performance on Part $V$ of the Token Test often reflects impaired syntactic processing. This study lends support to those conclusions.

The percent of memory and syntactic errors made on Parts IV and $V$ by the reading disabled and normal readers were also computed (See Figures 3 and 4 ). On Part IV, the reading disabled group made 93 errors which were evenly distributed among memory for shape (33\%), size (33\%), and color $(33 \%)$. The normal readers made 46 errors: 48 percent involved memory for size, 24 percent for memory for shape, and 28 percent for memory for color. An analysis of error types for the reading disabled group for Part $V$ showed that 54 percent of the 123 classified errors were syntactic errors. The remaining 31 percent were memory for shape errors and 15 percent were memory for color errors. The normal readers scored 65 percent of the 73 classified errors as syntactic errors, while 28 percent were memory for shape errors and 7 percent were memory for color errors. Visual inspection of these data (Figures 3 and 4 ) show that the reading disabled group had a different pattern of percert scores for Parts IV than for $V ;$ whereas, the normal reading group show a similar pattern of increasing steps from a low percentage to a high percentage for Parts IV and $V$. The even distribution of types of memory errors 


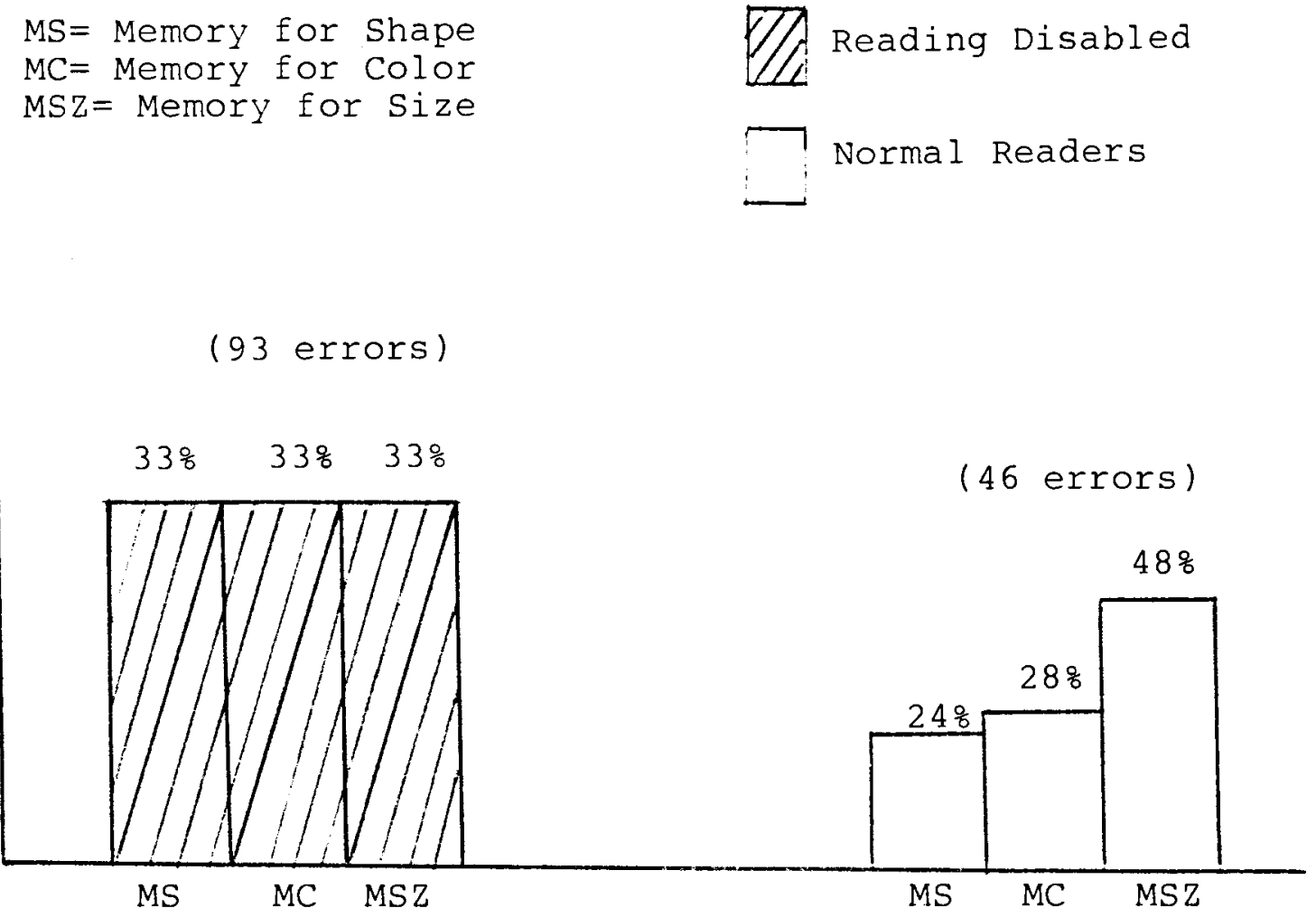

Fig. 3 Memory and Syntactic errors in Percent Scores for Reading Disabled and Normal Readers for Part IV.

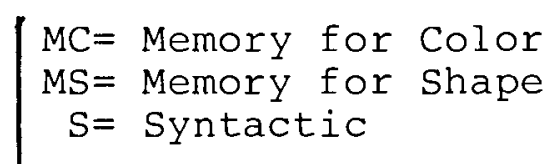

(123 errors)

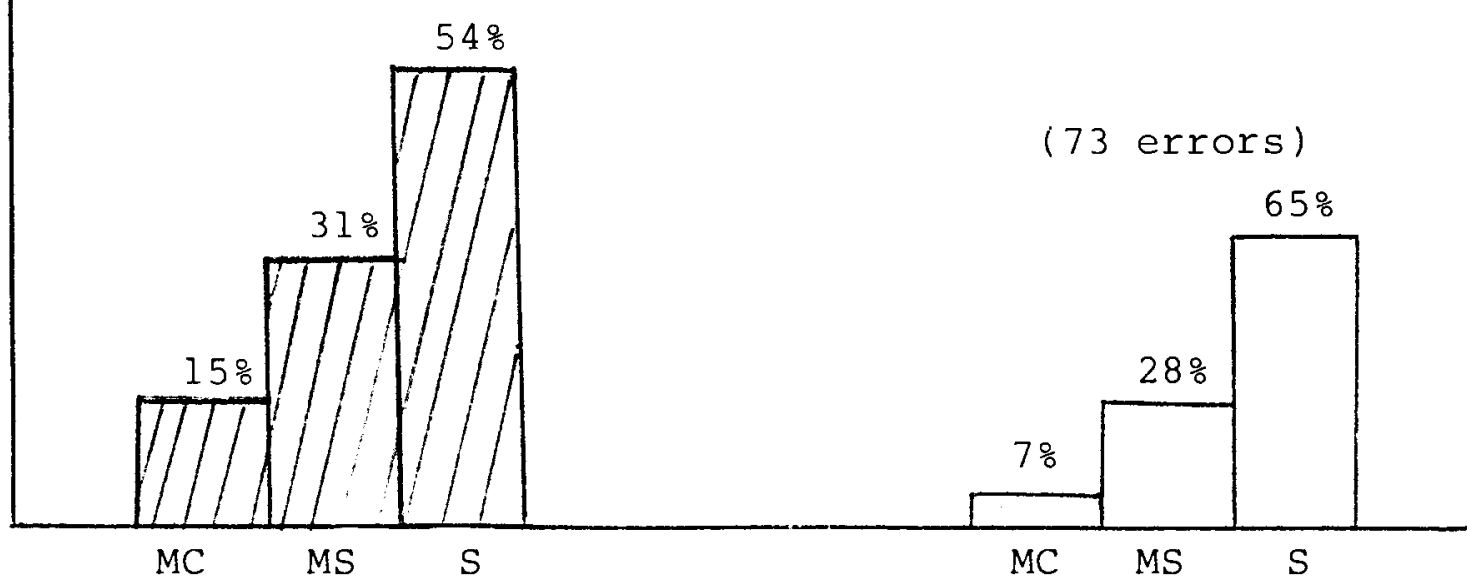

Fig. 4 Memory and Syntactic errors in Percent Scores for Reading Disabled and Normal Readers for Part V. 
on Part IV for the reading disabled group show that their memory errors are consistent across all three types of categories, i.e., shape, size, and color.

Further analysis of Part $V$ shows that reading disabled and normal readers had a higher percentage of error on memory for shape rather than on memory for color (Figure 4). According to DeRenzi and Vignolo (1962) who looked at aphasics' performance on the Token Test, their results revealed that "verbal expression for form," which in this study is described as shape, were understood less often than the others. They tentatively suggested that shape is possibly a more abstract concept than color or size and is being learned at a later age than size or color identification. With this implication, one can predict that because shape is a more difficult concept, more errors would result on this type of memory on this test, which is what occurred for all sbujects on Part $V$.

A subject-by-item analysis was done for Part $V$ only and the results showed that for the twenty-five reading disabled subjects, eleven made more syntactic errors than memory errors, twelve made more memory errors than syntactic errors and two made equal amounts of syntactic and memory errors (See Appendix F). The normal reading group breakdown is as follows: fourteen subjects made more syntactic errors than memory errors, six subjects made more memory errors than syntactic errors, and five subjects made equal amounts, of syntactic and memory errors (see Appendix Fl. Clearly it is shown that syntactic errors 
occurred more frequently in both groups. These results for both groups suggest that subgroups may be present as determined by the type of errors most commonly made. One subgroup of subjects did better on memory recall and the other group performed better on linguistic components. These subgroup formations of either poor memory or syntactic abilities support Wiig and semel (1980) in that children with learning disabilities show deficits in one or more language areas. Similarly, the whitehouse (1983) study cites the emergence of two subgroups from the dyslexic sample. One group showed impaired syntactic processing and one showed normal Token Test performance. However, there was a slight difference in the subgrouping from the Whitehouse (1983) study and this present study, in which only a subgroup of three reading disabled subjects performed similarly to normal readers. Hence, as stated by Whitehouse (1983), because dyslexia is a heterogeneous disorder, one would expect to see a variability in the type of errors.

Further analysis of Part $V$ shows that syntactic error types were predominant over memory errors for both the normal reading and reading disabled groups. The commands for Part $V$ require subjects to understand the syntactic complexity and recall the details of the command. The following paragraphs will discuss part $v$, item analysis for both groups.

On Part $V$, the items $3,5,13,18,19$, and 21 were found to be difficult for both groups. An analysis of 
these items shows that the verb "touch" was used for five of the six items. In parts I - IV, the verb "touch" was used from an implicit instrumental case (i.e., touching with the finger) and changed to an overt instrumental case (i.e., using the specified token to do the touching) in Part $\mathrm{V}$ (Whitehouse, 1983). The changing function of this verb may have presented a problem for both groups. Whitehouse (1983) clarifies that these commands may pose a confusion of static "touching" instead of the active "touch" (i.e., moving the two tokens together so they touch instead of using one as the instrument). The following discussion will review some common errors made by both groups and the variables which may have influenced the results.

The most common error on the items with the verb "touch" was to bring the tokens together simultaneously to touch each other rather than using a finger to touch the token or the specified token to perform the command. This was especially evident for item 3 ("Touch the blue circle with the red square") on which both groups made the most errors (reading disabled, 16 errors; and normal readers, 12 errors). The majority of the subjects from both groups touched the tokens together simultaneously or performed the command by incorrectly using the blue circle as the active agent instead of the red square. Disimoni (1978) states that the purpose of this command is to determine the child's ability to shift the function of the verb "touch" from its previous use in parts I - IV. As previousiy mentioned, this error analysis may be suggestive 
of difficulty in understanding syntactic structures.

As with item 3, item 5 ("Touch the blue circle and the red square") was frequently missed by both groups of subjects. Whitehouse (1983) found that this item also may be difficult because of the change of usage of the verb "touch" as from Parts I - IV. The most common error was to slide the two tokens together so they were touching. Apparently, due to the difficult syntactic nature in the shifting function of the verb "touch" of this command, many subjects erred on this item.

Another high error rate occurred on item 21 ("Before touching the yellow circle, pick up the red square") for both groups. The most common error task performed on this item was omitting the first phrase "Before touching the yellow circle" and only performing the second phrase "pick up the red square". Possible implications for this error suggests that the adverb "before" may have been understood and the act was being executed; however, due to a memory factor the subject did not complete the task. Another possible reason may be due to the syntactical complexity of the command involving the adverb "before" and the verb "touching" which may have been linguistically difficult for the subjects to understand. Lapointe (1976) suggests that the reading disability subjects in his study tended to ignore the logical relationship of the command with the use of the word "before" and did not perform simultaneous analysis and synthesis of this command.

An analysis of item 13 (" Touch the squares slowly and 
the circles quickly") showed that overall, subjects from both groups frequently omitted the plural "s" and touched only one square slowly and one circle quickly. Another common error was to slide the square tokens together slowly and slide the circles together quickly. According to Disimoni's (1978) scoring procedures, the verb "touch" in this task must show that the child touches the tokens with his or her fingers. If the child simultaneously slides the tokens together either quickly or slowly, the response is recorded incorrect. A possible explanation for the error on this item addresses the grammatical aspect of plurals. The literature reports that reading disabled children use less complex grammatical structures than normal readers and often have difficulty with morphological markers such as possessives, verb tense or plurals (Wiig, semel and Crouse, 1973; Vogel, 1975). However, the results indicated that the normal readers also frequently missed this item. It can be suspected that if the child anticipates touching the shapes quickly, he or she may perform the task carelessly. The presentation of the adverb "quickly" may facilitate a hurried response.

Two types of analyses were conducted to investigate whether a difference existed on syntactic and memory errors among grade levels ( 3 - 12) for the reading disabled students from this study who were in grades $3-6$ and dyslexic adolescents from the Whitehouse (1983) study who were in grades 7 - 12. The mean number of syntactic and memory errors did not significantly differ among grade levels 
(Table XI). The results support the wiig and semel (1975) study which suggests that between 75 and 85 percent of learning disabled youngsters experience significant delays in the acquisition of syntax and show language deficits that may persist into adolescence. The mean number of errors on Part $V$ of the Token Test for Children for each grade level of the reading disabled group was also analyzed (Table XII). Although the results from the previous analysis of the pooled sample for grades 3 - 12 was not statistically significant or more simply stated, the mean number of errors for each grade level did not vary significantly among the grade levels, it can be seen in Table XII that the error rate decreased as the grade level increased. These results may suggest that language deficits may continue into adolescence; however, as the individual gets older he or she tends to make fewer errors.

This study lends support to Flatcher, Satz, and Scholes's (1981) study in that reading abilities vary with the individual's age according to the acquisition of linguistic skills. More specifically, the performances by the reading disabled group and normal readers in grades $3-4$ (ages 9 - 10) revealed a higher number of syntactic errors for Part $V$ than the reading disabled and normal readers in grades 5 and 6 (ages 11 - 12) (See Appendix G). This may suggest that because older children are more developed in their linguistic skills, they consequently made fewer errors on syntax. 
Further analysis of this study suggests that both syntax and memory are important components for the development of receptive language abilities. Miller (1967) explains that syntax helps to structure or plan a series of previously unrelated words which in effect, helps the individual to chunk groups of words into grammatical units for the processing, retaining, and recalling of the stimuli. BriefIy, chunking is the grouping of three or four words or units together (Wiig and semel, 1976). As seen in this study, Parts I - IV include commands that are simple noun phrase and verb phrase structures and Part $V$ includes commands that become more complex grammatically and syntactically with the addition of conjunctions, adverbs, and prepositions. clearly the reading disabled group had more difficulty on the Token Test for Children, especially on Part $V$ in which the test commands became more grammatically complex and longer.

By way of summary, it can be seen that the error rates for both groups, reading disabled and normal readers, increased as each part of the test increased in length and complexity. However, from the statistical analysis, the reading djsabled group made a significantly higher number of syntactic and memory errors than the normal reading group. This supports the literature in that children and adolescents with learning disabilities display reductions in short term memory and difficulties in processing syntactic information (Wiig and Semel, 1976). Hence, it can be 
concluded that poor syntactic and memory abilities or both exist in children with reading disabilities; thus, the recognition of these language areas through the administration of the Token Test for Children an help in developing appropriate language programs. 
CHAPTER $V$

\section{SUMMARY AND IMPLICATIONS}

\section{Summary}

Many different versions of the original Token Test (De Renzi and Vignolo, 1962) have been available to speechlanguage pathologists as a language assessment tool with various populations. The most recently adapted version of the Token Test is the Token Test for Children developed by Disimoni (1978) as a measure to detect subtle receptive language abilities in children.

The purpose of this study was to determine if a significant difference existed between reading disabled and normal readers on syntactic and memory abilities on the Token Test for Children and if a difference existed between reading disabled students in grades $3-6$ and dyslexic adolescents in grades $7-12$ from the whitehouse (1983) study .

Twenty-five reading disabled subjects and twentyfive normal readers from grades $3-6$ participated in this study. Each subject met the criteria for the California Achievement Test scores (reading disabled, scores of 40 NCE or below; normal readers, scores within normal range), receptive vocabulary within one standard deviation, normal 
unilateral hearing, and a monolingual background. The Token Test for Children was administered individually and the results were scored and analyzed using Whitehouse's (1983) scoring system.

Subtest means and standard deviations, syntactic errors and memory errors, $t$-values, $\underline{z}$-values, and percent scores were compiled. Several $\underline{t}$-tests and $\underline{z}$-tests were conducted to determine if a difference existed between the mean number of syntactic and memory errors for both groups. The t-test results indicated a statistically significant difference on the mean number of syntactic and memory errors between the reading disabled and normal readers on the Token Test for chilaren beyond the 0.05 level of confidence. As anticipated, the reading disabled subjects made errors on the entire test, with more syntactic and memory errors on Part $V$. Further analysis of the test results showed that Part $V$, which increases in length and becomes more grammatically complex resulted with the highest number of errors for both groups. : It was also found that no significant difference was evident among grade levels for the reading disabled in grades 3 - 6 to dyslexic adolescents in grades $7-12$ from the whitehouse (1983) study. The results suggest that difficulties in language abilities continue into adojescence,

The overall performance of the reading disabled subjects revealed a higher number of syntactic and memory errors on the Token Test for Children in comparison with 
the normal reading group. The test results, particularly Parts IV and $V$, suggest that the Token Test for Children may help to identify subtle receptive language deficits in reading disabled children. Further research should investigate the language abilities in the areas of syntax and memory in children with learning disabilities on an age continuum.

\section{Implications}

\section{Clinical Implications}

The results of this study support the Whitehouse (1983) and Lapointe (1976) studies using the Token Test for Children as an instrument for measuring subtle receptive language abilities in learning disabled individuals. The Token Test for Children serves as a quick screening tool for assessing memory, as well as syntactical functions. Several components of this test offer practical assistance. First, it allows the investigation of memory recall of critical elements ranging in length from one to six critical elements. Secondly, it addresses the linguistic component that becomes increasingly complex as the command increases in length. Since both groups, reading disabled and normal readers, performed almost without error on Parts $I$ and II, it is possible to shorten the administration time by administering only Parts III - V after a pretest of color, size, and shape identification is completed. 
Research Implications

Further research possibilities may address the administration of the Token Test for Chilaren to those children who demonstrate behavioral problems. The results may suggest the relationship between the command length and complexity that children are abie to understand and remember. The consideration of syntactic complexity and memory recall factors may help to identify areas of weaknesses for this population.

Another consideration might be the presentation of the Token Test for children in conjunction with The Reporter's Test published by DeRenzi and Ferrari (1978). In the Reporter's Test, the examiner touches or manipulates the tokens according to the 26 items and the subjects then verbally describes the action. A testing procedure such as this may provide additional information of the oral expressive skill in addition to the receptive language functions in the reading disabled or learning disabled population.

Replication of this study to reading disabled and/or learning disabled youngsters in grades 1 and 2 is also indicated. The present study obtained and analyzed results for reading disabled students in grades $3-6$. The performance of children in grades 1 and 2 would contribute to the validity of the Token Test for Children and help to identify language deficits in areas of syntax and memory.

Further research may investigate whether there is a difference of scores when the Token Test for children test 
commands are presented with an imitative response from the subject. The results may reflect simultaneous analysis and synthesis of the commands and further imply whether poor performance reflects a central auditory processing problem.

The norming of the Token Test for Children on the basis of an additional scoring system similar to that of Whitehouse (1983) and Noll and Randolph (1978) consisting of memory for shape, size, and color errors and syntactic errors is also indicated. It would be interesting to see whether the specific scoring system helps to identify more subtle language deficits in children. Additional studies need to be conducted for the reliability of the Token Test for Children. 
BAKKER, D.J. (1979). Hemispheric differences and reading strategies: Two dyslexias? Bulletin of the orton Society, 14, 84-100.

BENDER, L.A. (1957). Specific reading disability as a maturational lag. Bulletin of the Orton Society, 7 , $9-18$.

BLACHMAN, B.A. (1983). Are we assessing the linguistic factors critical in early reading? Annals of Dyslexia, Vol. 33, 91-109.

BLOOM, L. (1975). Language development. In F.D. Horowitz (Ed.) Review of child develomment research. Chicago: Univ. of Chicago Press, Vol. 4.

CARTWRIGHT, L. and LASS, N. (1974). Comparative study of children's performance on the Token Test, Northwestern Syntax Screening Test, and Peabody Picture Vocabulary Test. Acta Symbolica, 5, 19-29.

CHALFANT, J.C. and SCHEFFELIN, M.A. (1969). "Central Processing Dysfunctions in Children: A Review of Research" NINDS monograph No. 9 Bethesda, Md: U.S. Department of Health, Education, and Welfare.

CHOMSKY, N. (1957). Syntactic Structures. The Hague: Mouton.

CHOMSKY, N. (1965). Aspects of the theory of syntax. Cambridge, Mass. The M.I.T. Press.

CRITCHLEY, M. (1970). The dyslexic chïld. William Heinemann Medical Books Limited, Jundon.

CRUIKSHANK, W.M. (1968). The problem of delayed recognition and its correction, In A.H. Keeney \& V.T. Keeney (Eds.), Dyslexia: Diagnosis and treatment of reading disorders. St. Louis, C.V. Mosby.

DELACATO, C.H. (1968). The treatment and prevention of reading problems. Springfield, Ill, Charles C. Thomas.

DeRENZI, E. and FERRARI, C. (1978). The Reporter's Test: A sensitive test to detect expressive disturbances in aphasics. Cortex, 14, 279-293.

DeRENZI, E. and Vignolo, L.A. (1962). The Token Tesi: A sensitive test to detect receptive disturbances in aphasics. Brain, 85, 665-678. 
DISIMONI, F. (1978). The Token Test for Children. Teaching Res. Boston, Mass.

DUNN, L.M. (1979). Peabody Picture Vocabulary Test (Rev. ed.) Circle Pines, MN: Holt, Rhinehart, and Winston.

FLETCHER, J.M. (1981). Linguistic factors in reading acquisition: Evidence for developmental changes. In F.J. Pirozzolo and M.C. Wittrock (Eds.), Neuropyschological and cognitive processes in reading. New York: Academic Press.

FLETCHER, J.M., SATZ, P. and SCHOLES, R.J. (1981). Developmental changes in the linguistic performance correlates of reading achievement. Brain and Language, 13, 78-90.

FROSTIG, M. (1972). Visual perception, integrative functions and academic learning. Journal of Learning Disabilities, $5,1-15$.

FRY, M.A., JOHNSON, C.S. and MUEHL, S. (1970). Oral language production in relationship to reading achievement among select second graders. In D.J. Bakker and P. Satz (Eds.) Specific reading disability: Advances in theory and method. Rotterdam: Rotterdam Univ. Press.

GIBSON, E. and LEVIN, H. (1975). The psychology of reading. Cambridge: The M.I.T. Press.

GROSS, K. and ROTHENBERG, S. (1979). An examination of methods used to test the visual perceptual deficit hypothesis of dyslexia. Journal of Learning Disabilities, $12,670-677$.

GUILFORD, J.(1973). Fundamental statistics in psychology and education. McGraw-Hill, New York.

HARRIS, A.J. (1982). How many kinds of reading disability are there? Journal of Learning Disabilities, 15, 456460 .

HERMANN, K. (1959). Reading disability. Copenhagen: Munksgaard.

HINSHELWOOD, J. (1917). Congenital Word Blindness. London: Lewis. In S. Vogel (Ed.) Syntactic abilities in normal and dyslexic children. University Park Press.

JOHNSON, D.J. and MYKLEBUST, H.R. (1967). Learning disabilities. New York: Grune and Stratton.

KEPHART, N. (1960). The slow learner in the classroom. Columbus, Ohio: Charles E. Merrill.

KINSBOURNE, M. and WARRINGTON, E.K. (1966). Developmental factors in reading and writing backwardness. In J: Money (Ed.) The Disabled Réader. Baltimore: The John Hopkins Press. 
LAPOINTE, C.M. (1976). Token test performance by learning disabled and achieving adolescents. British Journal of Communication, 11: 121-133.

LEE, L.L. (1969). Northwestern Syntax Screening Test. Evanston, Illinois: Northwestern University Press.

LEVINSON, H.N. (1980). A solution to riddle dyslexia. New York: Springer-Verlag.

LIBERMAN, I.Y. (1982). A language-oriented view of reading and its disabilities. In H. Myklebust (Ed.) Progress in Learning Disabilities. (Vol. 5) New York: Grune and Stratton.

LIPA, S.E. (L983). Reading disability: A new look at an old issue. Journal of Learning Disabilities, 16, 453-457.

MALATESHA, R.N. and DOUGAN, D.R. (1982). Clinical subtypes of developmental dyslexia: Resolution of an irresolute problem. In R.N. Malatesha and P.G. Aaron (Eds.) Reading disorders: Varieties and treatments. Academic Press, Inc.

MARSHALL, J.C. and NEWCOMBE, F. (1973). Patterns of paralexia: A psycholinguistic approach. Journal of Psycholinguistic Research, 2, 175-195.

MCNEIL, M. and PRESCOTT, T. (1978). Revised Token Test. Baltimore, Maryland, University Park Press.

MENYUK, P. and LOONEY, P. (1972). A problem of language disorder: Length versus structure. Journal of Speech and Hearing Research, 15, 264-279.

MEYERS, P.I. and HAMMILI, D.D. (1976). Methods for learning disorders. John Wiley and Sons, Inc.

MILLER, G.A. (1967). The psychology of communication. Basic Books Inc., Publishers, New York.

NOLI, J.D. and RANDOLPH, S.R. (1978). Auditory semantic, syntactic, and retention errors made by aphasic subjects on the Token Test. Journal of Communication Disorders, $11,543-553$.

ORTON, A.T. (1937). Reading, writing and speech problems in children. New York: W.W. Norton. In S. Vogel (Ed.) Syntactic abilities in normal and dyslexic children. Univ. Park Press, BaItimore, MD.

PERFETTI, C.A. and LESGOLD, A.M. (1979). Coding and comprehension in skilled reading and implications for reading instruction. In L.B. Resnick and P.A. Weaver (Eds.) Theory and practice of early reading. Vol. 1, Hilisdale, N.J.: Lawrence Erlbaum Associates. 
PIROZZOLO, F.J. (1979). The neuropsychology of developmental reading disorders. New York: Praeger.

POECKM, K. ORGASS, B., KERSCHENSTEINER, M., anā HARTJE, W. (1974). A qualitative study on Token Test performance in aphasic and nonaphasic brain damaged patients. Neuropsychologia, 12,49-54.

RABINOVITCH, R. (1968). Reading problems in children: Definitions and classifications. In $A$. Keeney and $V$. Keeney (Eds.) Dyslexia. St. Louis: C.V. Mosby.

RABINOVITCH, R.D. and INGRAM, W. (1968). Neuropsychiatric considerations in reading retardation. In $G$. Natchez (Ed.) Children with reading problems. New York. Basic Books.

RUDEL, R. (1966). Reading instruction in first grade with varying emphasis on the regularity of grapheme-phoneme correspondences and the relationship of language structure to meaning. The Reading Teacher, 19, 653-660.

RUDEL, R. (1968). The relation of regularity of graphemephoneme correspondence and of language structure to achievement in first grade reading. In $K$. Goodman (Ed.) The psycholinguistic nature of the reading process. Detroit: Wayne state University Press.

SATZ, P. and FLETCHER, J.M. (1980). Minimal brain dysfunction: An appraisal of research concepts and methods. In $H$. Rie and E. Rie (Eds.) Handbook of minimal brain dysfunctions: A critical view. New York: Wiley-Interscience.

SATZ, P., TAYLOR, H.G., FRIEL, J., and FLETCHER, J.M. (1978). Some developmental and predictive precursors of reading disabilities: A six year follow-up. In A.L. Benton and D. Pearl (Eds.) Dyslexia: An appraisal of current knowledge. New York, Oxford University Press.

SATZ, P. and VAN NOSTRAND, G.K. (1973). Developmental dyslexia: An evaluation of a theory. In P. Satz and J. Ross (Eds.) The disabled learner: Early detection and intervention. Rotterdam, University Press.

SEMEL, E.S. and WIIG, E.H. (1975). Comprehension of syntactic structures and critical verbal elements by children with learning disabilities. Journal of Learning Disabilities, $8,46-58$.

TALLAL, P. (1975). Perceptual and linguistic factors in the language impairment of developmental dysphasics: An experimental investigation with the Token Test. Cortex, $11,196-205$. 
TORGESEN, J.K. (1975). Problems and prospects in the study of learning disabilities. In M.G. Hetherington (Ed.) Review of child development research. Chicago; Univ. of Chicago Press. vol 5.

VELLUTINO, F.R. (1978). Toward an understanding of dyslexia: Psychological factors in specific reading disability. In A.L. Benton and D. Pearl (Eds.) Dyslexia: An appraisal of current knowledge. New York: Oxford Univ. Press.

VELLUTINo, F.R. (1979). Dyslexia: Theory and Research. Cambridge, Mass. M.I.T. Press.

VOGEL, S. (1974). Syntactic abilities in normal and dyslexic children. Journal of Learning Disabilities, 7, 47-51.

VOGEL, S. (1975). Syntactic abilities in normal and dyslexic children. University Park Press, Baltimore, MD.

WHITAKER, H.A. and WHITAKER, H. (1979). Lexical, syntactic, and semantic aspects of the Token Test: A linguistic taxonomy. In F. Boller and M. Dennis (Eds.) Auditory Comprehension: Clinical and experimental studies with the Token Test. Academic Press, Inc. New York.

WHITEHOUSE, C.C. (1983). Token Test performance by dyslexic adolescents. Brain and Language, 18, 224-235.

WIIG, E.H., LAPOINTE, C. and SEMEL, E.M. (1975). Relationships among language processing and production abilities of learning disabled adolescents. In E.H. Wiig and E.M. Semel (Eds.) Language Disabilities in Children and Adolescents. Charles E. Merrill Publishing Company.

WIIG, E.H. and ROACH, M.A. (1.975). Inmediate recall of semantically and syntactically varied "sentences" by learning disabled adolescents. Perceptual and Motor Skills, 40, 119-125.

WIIG, E.H. and SEMEL, E.M. (1975). Comprehension of syntactic structures and critical verbal elements by children with learning disabilities. Journal of Learning Disabilities, $8,46-58$.

WIIG, E.H. and SEMEL, E.M. (1975). Ianguage Disabilities in Children and Adolescents. Charies E. Merrill Publishing Company, Columbus, Ohio.

WIIG, E.H. and SEMEL, E.M. (1980). Language Assessment and Intervention for the Learning Disabled. Charles E. Merrill Publishing Company.

WIIG, E.H., SEMEL, E.M. and CROUSE, M.B. (1973). The use of English morpholoyy by high risk and learning disabled children. Journal of Learning Disabilities, 6, 457-465. 
Appendix A

Permission Request Letter

\section{Dear Parent or Guardian,}

I am a graduate student of speech-language pathology at Portland State University in the process of writing my thesis for the master's degree fulfillments. I am conducting a study of the performance of children ages nine to twelve in grades $3-6$ on the Token Test for Children. The Token Test for Chilaren is a test of language understanding which requires the child to manipulate colored shapes upon given instructions.

This study includes a brief 10 - 15 minute screening using a speech-language test (The Peabody Picture Vocabulary Test) and a hearing screening test given by myself. Some children will then be randomly selected to participate further in the study. They will be administered the Token Test for Children by me during a $10-15$ minute period. The results of this test will only be used for the purpose of this study.

There are no risks involved and in no way will you child's name be used in reporting the results of this study. At any time you may withdraw your child from the study without jeopardizing his or her position in school.

If you have any questions regarding your child's participation in this study, feel free to contact me at 241-2552; my advisor, Ms. Mary Gordon at 229-3533; or Ms. Karen Jenkins, Speech-Language Pathologist at this school at 654-2830. If you wish your child to be a part of this study, please sign below indicating your approval and return this portion to school with your child tomorrow. I would greatly appreciate your permission for your child's involvement in this study. The findings of this study will help us more clearly understand the language abilities of children. Thank you for your cooperation.

$$
\text { Sincerely, }
$$

Karen L. Jenkins, M.S., CCC

Speech-Lang. Pathologist

Oregon City School District
Jane J. Kihara

Graduate student, Speech-Pathology

Portland State University

I permit my child, to participate in this study.

in grade

Please check: our family speaks Standard American English at home. our family speaks more than one language at home (e.g., Spanish, Chinese, German, etc.) 


\section{Appendix B}

Test Commands

\section{Part I}

1. Touch the red circle.

2. Touch the green square.

3. Touch the red square.

4. Touch the yellow circle.

5. Touch the blue circle.

6. Touch the green circle.

7. Touch the yellow square.

8. Touch the white circle.

9. Touch the blue square.

10. Touch the white square.

\section{Part II}

1. Touch the small yellow circle.

2. Touch the large green circle.

3. Touch the large yellow circle.

4. Touch the large blue square.

5. Touch the small green circle.

6. Touch the large red circle.

7. Touch the large white square:

8. Touch the small blue circle.

9. Touch the small green square.

10. Touch the large blue circle.

\section{Part III}

1. Touch the yellow circje and the red square.

2. Touch the green square and the blue circle.

3. Touch the blue square and the yellow square.

4. Touch the white square and the red square

5. Touch the white circle and the blue circle.

6. Touch the blue square and the white square.

7. Touch the blue square and the white circle.

8. Touch the green square and the blue circle.

9. Touch the red circle and the yellow square.

10. Touch the red square and the white circle.

\section{Part IV}

1. Touch the small yellow circle and the large green square.

2. Touch the small blue square and the small green circle.

3. Touch the large white square and the large red circle.

4. Touch the large blue square and the large red square.

5. Touch the small blue square and the small yellow circle.

6. Touch the small blue circle and the small red circle.

7. Touch the large blue square and the large green square.

8. Touch the large blue circle and the large green circle. 
9. Touch the small red square and the small yellow circle.

12. Touch the small white square and the large red square.

Part V

1. Put the red circle on the green square.

2. Put the white square behind the yellow circle.

3. Touch the blue circle :ith the red square.

4. Touch- with the blue circle- the red square.

5. Teuch the blue circle and the red square.

6. Pick up the olue circle or the red square.

7. Put the green square away from the yellow square.

8. Put the white circle in front of the blue square.

9. If there is a black circle, pick up the red square.

10. Pick up the squares, except the yellow one.

11. When I touch the green circle, you take the white square.

12. Put the Ereen square beside the red circle.

13. Touch the squares slowly and the circles quickly.

14. Put the red circle between the yellow square and the green square.

15. Except for the green one, touch the circles.

16. Pick up the red circle- No! - the white square.

17. Instead of the white square, take the yellow circle.

18. Together with the yellow circle, take the blue circle.

19. After picking up the green square, touch the white circle

20. Put the blue circle underneath the white square.

21. Before touching the yellow circle, pick up the red square. 


\section{Appendix C}

Total Test Scores on the Token Test

for Children for Reading Disabled Subjects $\mathrm{N}=25$

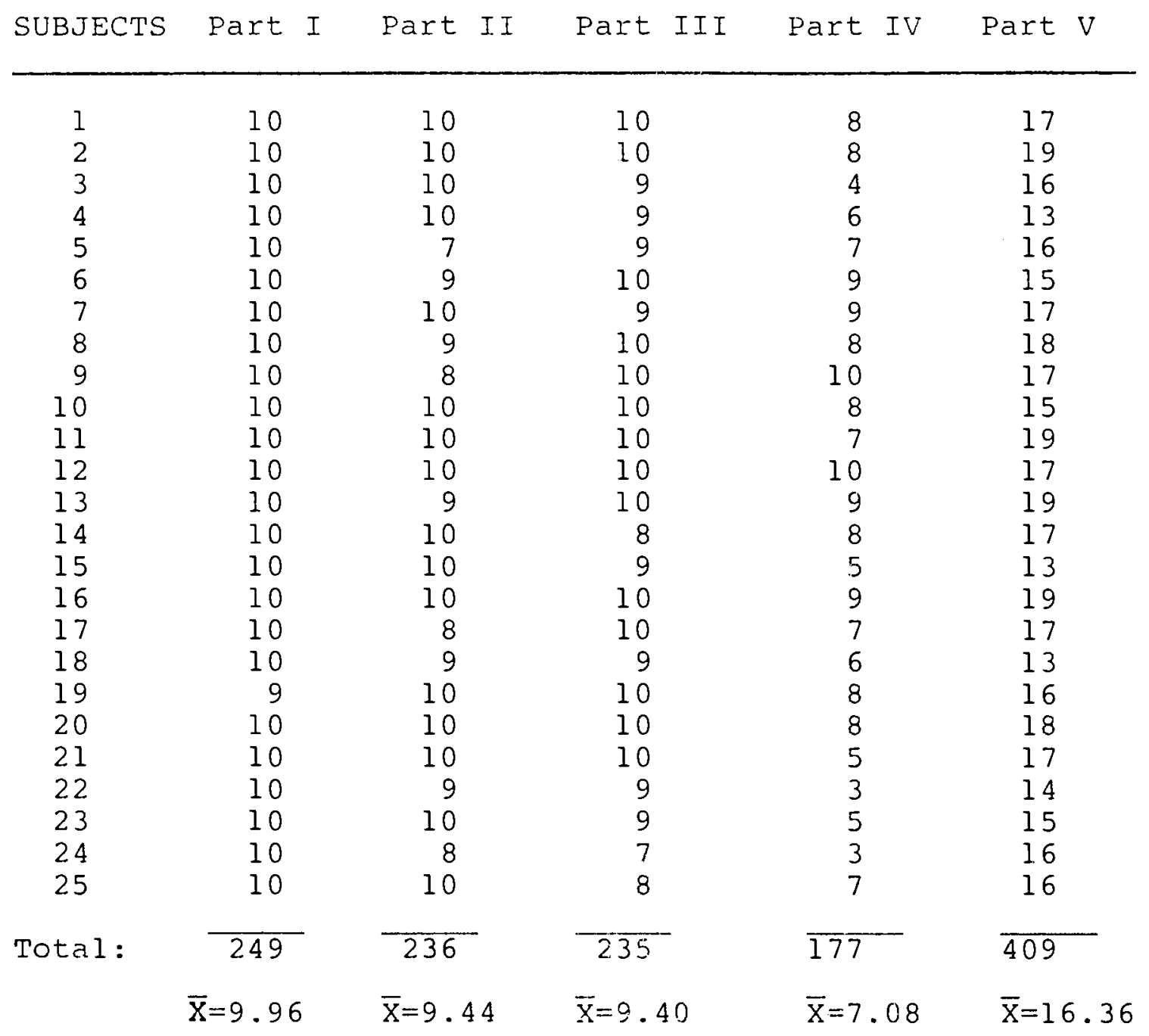


Appendix D

Total Test Scores on the Token Test for Children for Normal Readers $\mathrm{N}=25$

SUBJECTS Part I Part II Part III Part IV Part V

\begin{tabular}{|c|c|c|c|c|c|}
\hline 1 & 10 & 10 & 10 & 10 & 21 \\
\hline 2 & 10 & 10 & 10 & 9 & 17 \\
\hline 3 & 10 & 10 & 10 & 10 & 20 \\
\hline 4 & 10 & 10 & 8 & 6 & 18 \\
\hline 5 & 10 & 10 & 10 & 10 & 19 \\
\hline 6 & 10 & 10 & 10 & 8 & 21 \\
\hline 7 & 10 & 9 & 10 & 9 & 16 \\
\hline 8 & 10 & 10 & 10 & 9 & 19 \\
\hline 9 & 10 & 10 & 10 & 9 & 19 \\
\hline 10 & 10 & 10 & 10 & 8 & 19 \\
\hline 11 & 10 & 10 & 10 & 10 & 20 \\
\hline 12 & 10 & 10 & 10 & 10 & 20 \\
\hline 13 & 10 & 10 & 10 & 9 & 17 \\
\hline 14 & 10 & 10 & 10 & 6 & 19 \\
\hline 15 & 10 & 10 & 10 & 9 & 19 \\
\hline 16 & 10 & 10 & 10 & 7 & 19 \\
\hline 17 & 10 & 10 & 10 & 9 & 17 \\
\hline 18 & 10 & 9 & 10 & 8 & 19 \\
\hline 19 & 10 & 10 & 9 & 8 & 14 \\
\hline 20 & 10 & 10 & 9 & 8 & 20 \\
\hline 21 & 10 & 10 & 9 & 7 & 16 \\
\hline 22 & 10 & 10 & 10 & 10 & 20 \\
\hline 23 & 10 & 9 & 10 & 8 & 17 \\
\hline 24 & 10 & 10 & 9 & 6 & 15 \\
\hline 25 & 10 & 10 & 9 & 5 & 17 \\
\hline \multirow[t]{2}{*}{ Total: } & 250 & 247 & 243 & 208 & 458 \\
\hline & $\bar{X}=10$ & $\bar{X}=9.88$ & $\bar{X}=9.72$ & $\bar{X}=8.32$ & $\bar{X}=18.32$ \\
\hline
\end{tabular}


Appendix E

Total Test Scores on Memory and Syntactic Errors for Both Groups

\begin{tabular}{|c|c|c|c|c|c|}
\hline \multirow[b]{2}{*}{ SUBJECT } & \multicolumn{2}{|c|}{ READING DISABLED } & \multicolumn{3}{|c|}{ NORMAL READERS } \\
\hline & Memory & Syntactic & SUBJECT & Memory & Syntactic \\
\hline$I$ & 5 & 1 & 1 & 2 & 3 \\
\hline 2 & 2 & 2 & 2 & 0 & 0 \\
\hline 3 & 9 & 5 & 3 & 6 & 3 \\
\hline 4 & 15 & 2 & 4 & 1 & 0 \\
\hline 5 & 6 & 1 & 5 & 2 & 3 \\
\hline 6 & 0 & 4 & 6 & 0 & 1 \\
\hline 7 & 3 & 2 & 7 & 0 & 1 \\
\hline 8 & 5 & 3 & 8 & 5 & 1 \\
\hline 9 & 4 & 2 & 9 & 2 & 2 \\
\hline 10 & 3 & 3 & 10 & 3 & 1 \\
\hline 11 & 5 & 2 & 11 & 6 & 2 \\
\hline 12 & 6 & 3 & 12 & 2 & 0 \\
\hline 13 & 11 & 3 & 13 & 1 & 1 \\
\hline 14 & 8 & 1 & 14 & 1 & 2 \\
\hline 15 & 13 & 2 & 15 & 6 & 2 \\
\hline 16 & 1 & 2 & 16 & 5 & 5 \\
\hline 17 & 5 & 4 & 17 & 4 & 1 \\
\hline 18 & 4 & 4 & 18 & 2 & 3 \\
\hline 19 & 13 & 4 & 19 & 3 & 3 \\
\hline 20 & 17 & 5 & 20 & 6 & 2 \\
\hline 21 & 6 & 4 & 21 & 4 & 0 \\
\hline 22 & 3 & 3 & 22 & 9 & 2 \\
\hline 23 & 7 & 5 & 23 & 7 & 6 \\
\hline 24 & 19 & 0 & 24 & 3 & 3 \\
\hline 25 & 12 & 3 & 25 & 1 & 0 \\
\hline \multirow[t]{2}{*}{ Total } & 182 & 70 & & 81 & 47 \\
\hline & $\bar{X}=7.28$ & $\bar{X}=2.8$ & & $\bar{X}=3.24$ & $\bar{X}=1.88$ \\
\hline
\end{tabular}


Appendix $F$

Reading Disabled and Normal Readers Individual Syntactic and Memory Error Count on Part $V$

\begin{tabular}{|c|c|c|c|c|c|}
\hline \multirow[b]{2}{*}{ SUBJECT } & \multicolumn{2}{|c|}{$\underline{\text { READING DISABLED }}$} & \multicolumn{3}{|c|}{ NORMAL READERS } \\
\hline & Syntactic & Memory & SUBJECT & Syntactic & Memory \\
\hline 1 & 2 & 3 & 1 & 0 & 1 \\
\hline 2 & 5 & 5 & 2 & 3 & 0 \\
\hline 3 & 2 & 0 & 3 & 3 & 1 \\
\hline 4 & 1 & 3 & 4 & 0 & 0 \\
\hline 5 & 2 & 3 & 5 & 1 & 1 \\
\hline 6 & 3 & 5 & 6 & 2 & 4 \\
\hline 7 & 2 & 3 & 7 & 0 & 0 \\
\hline 8 & 3 & 0 & 8 & 1 & 2 \\
\hline 9 & 2 & 2 & 9 & 2 & 1 \\
\hline 10 & 2 & 4 & 10 & 1 & 1 \\
\hline 11 & 1 & 2 & 11 & 4 & 1 \\
\hline 12 & 4 & 0 & 12 & 1 & 0 \\
\hline 13 & 2 & 0 & 13 & 0 & 1 \\
\hline 14 & 4 & 5 & 14 & 3 & 1 \\
\hline 15 & 5 & 0 & 15 & 3 & 2 \\
\hline 16 & 1 & 4 & 16 & 2 & 1 \\
\hline 17 & 2 & 5 & 17 & 4 & 3 \\
\hline 18 & 2 & 0 & 18 & 2 & 1 \\
\hline 19 & 4 & 1 & 19 & 2 & 0 \\
\hline 20 & 3 & 4 & 20 & 0 & 1 \\
\hline 21 & 0 & 6 & 21 & 3 & 0 \\
\hline 22 & 5 & 1 & 22 & 5 & 0 \\
\hline 23 & 5 & 2 & 23 & 1 & 1 \\
\hline 24 & 4 & 0 & 24 & 2 & 0 \\
\hline 25 & 3 & 0 & 25 & 0 & 1 \\
\hline Total & 69 & 58 & & 45 & 24 \\
\hline
\end{tabular}

Subject count of highest type of error:

Syntactic $=11$ subjects Memory = 12 subjects

Equal amount $=2$ subjects
Syntactic $=14$ subjects Memory $=6$ subjects Equal amount $=5$ subjects 
Appendix G

Memory and syntactic Errors for Reading Disabled and Normal Readers

by Grade Levels for Part $V$

\section{READING DISABLED}

Grades

6

5

4

3

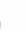

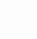

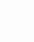

Syntactic Errors

$\left.\begin{array}{l}10 \\ 22\end{array}\right\} 32$

$\left.\begin{array}{l}18 \\ 20\end{array}\right\} 28$
Memory Errors

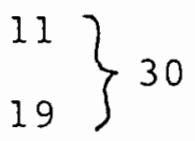

$\left.\begin{array}{l}15 \\ 13\end{array}\right\} 28$

\section{NORMAL READERS}

Grades

6

5

4

3
Syntactic Errors

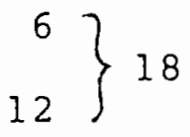

$\left.\begin{array}{l}16 \\ 12\end{array}\right\} 28$
Memory Errors

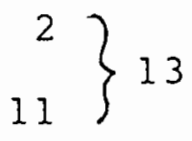

$\left.\begin{array}{l}8 \\ 3\end{array}\right\} 11$ 